\title{
El deterioro de las capacidades técnico-operativas de las empresas públicas argentinas durante la última dictadura cívico-militar (1976-1983)^
}

\author{
The deterioration of the technical-operational capacities of \\ Argentine state-owned enterprises during the last civic-military \\ dictatorship (1976-1983)
}

\author{
Débora Ascencio $\star \star$
}

Resumen: El propósito de este artículo es analizar las capacidades técnico-operativas de diez de las principales empresas públicas argentinas durante la última dictadura cívico-militar (1976-1983), a partir de examinar su desempeño en una serie de indicadores productivos y laborales. Como resultado, se destaca un cambio cualitativo en la relación producción-empleo. Durante los años previos al golpe de Estado, el incremento (más moderado) en la productividad laboral fue acompañado de un crecimiento en la producción y en el empleo. En contraste, entre 1974 y 1983 se constata un aumento en el volumen fisico de la producción junto con una significativa y generalizada contracción en la dotación de trabajadores y sus remuneraciones. Esto conllevó un aumento en la explotación de la fuerza de trabajo y el retroceso en las capacidades técnico-operativas de las firmas.

Palabras clave: Empresas públicas. Desempeño técnico-operativo. Capacidades estatales- dictadura cívico-militar.

Abstract: The purpose of this article is to analyze the technical-operational capacities of ten of the main Argentine state-owned enterprises during the last civil-military dictatorship (1976-1983), by examining their performance in a series of productive and labor indicators. As a result, a qualitative change in the production-employment relationship is highlighted. During the years prior to the coup d'état, the (more moderate) increase in labor productivity was accompanied by

\footnotetext{
* Submissão: 25/01/2021 | Aprovação: 13/08/2021 | DOI: 10.29182/hehe.v24i3.797

El artículo retoma algunos resultados de la tesis de Maestría en Sociología Económica (IDAES-UNSAM) defendida en diciembre de 2020 y también del trabajo doctoral en curso.

$\star \star$ Becaria doctoral del Consejo Nacional de Investigaciones Científicas y Técnicas (CONICET) con sede en el Centro de Innovación de los Trabajadores (CITRA). Doctoranda en Ciencias Sociales y docente en la Facultad de Ciencias Sociales, Universidad de Buenos Aires (UBA) | E-mail: deborascencio@gmail.com
} 
growth in production and employment. In contrast, between 1974 and 1983 there was an increase in the physical volume of production together with a significant and generalized contraction in the number of workers and their salaries. This led to an increase in the labor force exploitation and a decline in the technical-operational capacities of the firms.

Keywords: State-owned enterprises. Technical-operational performance. State-capacities. Civic-military dictatorship.

JEL: N76. 


\section{Introducción}

A partir del golpe de Estado de 1976, en Argentina, se produjeron transformaciones de gran magnitud en el tipo de intervención económica estatal que trastocaron la lógica de funcionamiento del patrón de acumulación de capital. La gestión económica liderada por el Ministro José Alfredo Martínez de Hoz implementó una serie de reformas estructurales inspiradas en la nueva corriente ortodoxa conocida como "Escuela de Chicago". ${ }^{2}$ Estas medidas posibilitaron cambios radicales en el régimen de acumulación sobre la base de cuatro ejes: 1) liberalización de todos los precios de la economía, con excepción de los salarios; 2) instrumentación de una reforma financiera; ${ }^{3}$ 3) una tasa de cambio basada en devaluaciones decrecientes en el tiempo (conocida como "tablita" cambiaria); 4) apertura de la economía a los flujos internacionales de bienes y de capitales (Castellani, 2006). La combinación de estos factores desmanteló la estrategia de industrialización por sustitución de importaciones característica de las décadas previas y configuró un nuevo patrón de acumulación centrado en los mecanismos de valorización financiera del capital ${ }^{4}$ (Azpiazu y Schorr, 2010; Basualdo, 2013; Iramain, 2014; Schvarzer, 1998).

Ahora bien, en la literatura sobre la política económica de la última dictadura argentina se resalta su carácter dual (Canitrot, 1980; Pucciarelli,

\footnotetext{
${ }^{1}$ Fue el primer Ministro de Economía del gobierno de facto -en rigor, lo antecedió por sólo 5 días Joaquín de Las Heras-, bajo la presidencia del militar Jorge Rafael Videla y su gestión se extendió desde marzo de 1976 hasta marzo de 1981, año en el que se produjo una aguda crisis económica. Luego, lo sucedieron en la cartera económica Lorenzo Sigaut, desde abril a diciembre de 1981 (presidencia del militar Roberto Viola); Roberto Aleman, desde diciembre de 1981 hasta julio de 1982 (presidencia del militar Leopoldo Fortunato Galtieri); José María Dagnino Pastore, desde julio a agosto de 1982 y Jorge Wehbe desde agosto de 1982 hasta diciembre de 1983 (presidencia de Reynaldo Bignone).

${ }^{2}$ Según Heredia (2004), la gestión económica de Martínez de Hoz fue: "un espacio de convivencia entre dos tipos de liberales: los tradicionales, representantes exclusivos hasta entonces de la filosofía de libre mercado, y los tecnocráticos que, luego de hacer su primera experiencia durante el gobierno de la dictadura, se consolidaron como los portavoces más dinámicos y eficientes del discurso antiestatista con la llegada de la democracia" (p. 316).

${ }^{3}$ Mediante la sanción de dos leyes: la 21.495/77 sobre la descentralización de los depósitos y la 21. 526/77 sobre el nuevo régimen de entidades financieras.

${ }^{4}$ Eduardo Basualdo define a la valorización financiera como “....un proceso en el cual las fracciones del capital dominante contrajeron deuda externa para luego realizar con esos recursos colocaciones en activos financieros en el mercado interno (títulos, bonos, depósitos, etc.) para valorizarlos a partir de la existencia de un diferencial positivo entre la tasa de interés interna e internacional y posteriormente fugarlos al exterior. De esta manera, a diferencia de lo que ocurría durante la segunda etapa de sustitución de importaciones, la fuga de capitales al exterior estuvo intrínsecamente vinculada al endeudamiento externo porque esto último ya no constituyó, en lo fundamental, una forma de financiamiento de la inversión o del capital de trabajo sino un instrumento para obtener una renta financiera dado que la tasa de interés interna (a la cual se coloca el dinero) era sistemáticamente superior al costo del endeudamiento externo en el mercado internacional" (Basualdo, 2010, p. 449).
} 
2004; Schvarzer, 1986). Las reformas de corte liberal-aperturista impulsadas por la nueva tecnocracia liberal al frente de la cartera económica convivieron con medidas de cuño intervencionista promovidas por ciertos sectores de las Fuerzas Armadas y la burocracia estatal, configurando lo que Schvarzer, (1981) denominó como complejo económico estatal-privado. ${ }^{5}$ De todos los mecanismos de transferencia de recursos públicos hacia el sector privado asociados a la ampliación del complejo, la privatización periférica fue el que afectó más directamente a las empresas públicas bajo análisis. La política se basó en la transferencia de operaciones desde el Estado hacia los privados en una constante pérdida de capacidades estatales de las firmas involucradas, transfiriendo los negocios más rentables en los que el Estado había invertido o explorado previamente (Castellani; Iramain, 2018; Iramain, 2014). Esto conllevó, además, una política de precios muy perjudicial para las empresas estatales, que se verá reflejada en el derrotero de los precios y tarifas de las firmas de la muestra.

Esta batería de medidas alteró profundamente la estructura económico-social en base a la concentración y centralización de capital, la redistribución regresiva del ingreso y un cambio en la naturaleza de las crisis del sector externo ${ }^{6}$ (Basualdo, 2010; Schorr, 2012; Schvarzer, 1986). En lo relativo al mercado laboral, se trastocaron los patrones tradicionales de movilidad social. En la nueva dinámica especulativa, el salario perdió su importancia como dinamizador de la demanda interna y elemento indispensable para la realización del excedente (Castellani, 2006). Entre 1974 y 1983 se produjo una caída de 22 puntos porcentuales de los asalariados en el ingreso nacional y un retroceso cercano al $40 \%$ en el salario real.También se contrajo el empleo formal, particularmente el industrial y se deterioró la calidad en el empleo

\footnotetext{
${ }^{5}$ El complejo económico estatal-privado hace referencia al conjunto de actividades desarrolladas por empresas públicas, privadas y mixtas que operaban en las ramas más dinámicas de la industria, en el sector petrolero, en la construcción de obras públicas y en algunos servicios claves como la electricidad, la provisión de gas y las comunicaciones. La realización de estas actividades implicaba, generalmente, la existencia de vinculaciones preferenciales entre el sector público y ciertas fracciones del sector privado (especialmente, los grupos económicos locales) que permitieron la expansión de las firmas privadas gracias a la conformación de contextos de acumulación privilegiados. Además de la privatización periférica, otras formas de ampliación de actividades en torno al complejo fueron el aumento de la inversión pública en infraestructura y la concesión de obras por el sistema de peaje, que generaron cuantiosas demandas sobre las grandes empresas constructoras y cementeras del país y la promoción industrial para ciertos sectores considerados estratégicos para la actividad militar (Schvarzer, 1979; Castellani, 2004).

${ }^{6}$ Durante la industrialización por sustitución de importaciones, el incremento del endeudamiento externo se producía casi exclusivamente cuando las importaciones superaban a las exportaciones, esto se daba periódicamente generando una crisis de la balanza de pagos y dando lugar a procesos recesivos. Este comportamiento, que prevaleció durante décadas, no se repitió a partir de 1979 porque el aceleradísimo endeudamiento externo se inició en una situación caracterizada por todo lo contrario, es decir, con un superávit de la balanza comercial y una inédita disponibilidad de reservas internacionales (Basualdo, 2000).
} 
generado debido a un incremento del empleo informal y autónomo (Arceo et al., 2008 y Iramain, 2014). En lo relativo a la política laboral, se sancionaron una serie de normas que cercenaron los derechos básicos de los trabajadores como el derecho a huelga, la intervención de la Central General de los Trabajadores (CGT) y la supresión de las negociaciones colectivas de salarios. ${ }^{7}$ Estas transformaciones transcurrieron en paralelo a la ejecución de un plan represivo feroz contra los sectores populares y el "disciplinamiento" al interior de los lugares de trabajo (Robertini, 2016; Simonassi, 2007). Inclusive, ese "disciplinamiento" alcanzó al empresariado menos concentrado, tal como analizó Canitrot, (1980) en su texto pionero.

Si bien la literatura especializada abordó de manera muy prolífera los efectos de estos cambios en la estructura productiva y el mercado de trabajo, el foco de los estudios estuvo en el sector privado ${ }^{8}$.Tal como advierten Castellani e Iramain (2018), existe una vacancia notable en torno al impacto de dichas transformaciones en los desempeños y capacidades de las empresas y organismos públicos en general. En ese sentido, el propósito de este artículo es analizar las capacidades técnico-operativas de las principales empresas públicas de la Sindicatura General de Empresas Públicas (SIGEP). Las firmas de la SIGEP constituyen un observable adecuado de la política implementada por el Ministerio de Economía hacia las empresas públicas, dado que nucleó todas las firmas de propiedad estatal que dependían de dicha cartera. ${ }^{9}$ En un contexto en el que la política económica estuvo atravesada por internas y disputas cruentas (Canelo, 2008), resulta pertinente diferenciar el objeto de estudio

\footnotetext{
${ }^{7}$ Mediante la Ley 21.261 se suprimió el derecho a huelga y la realización de cualquier tipo de medida de fuerza. Luego, con la Ley 21.400 la huelga fue transformada en delito penal. También se dispuso mediante la Ley 21.270 la intervención de la Confederación General del Trabajo (CGT), la derogación del fuero gremial de los representantes sindicales y el bloqueo de fondos, cuentas bancarias y patrimonio de la CGT. Las negociaciones colectivas de salarios fueron prohibidas mediante la Ley 21.307, tanto en el sector público como en el sector privado. También se suprimieron y modificaron elementos importantes de la Ley de Contratos de Trabajo que vulneraron gran cantidad de derechos laborales (Iramain, 2014; Recalde, 2013).

${ }^{8}$ Más específicamente, en el impacto regresivo y heterogéneo sobre la industria y el esquema de ganadores y perdedores como resultado de las transformaciones estructurales (Azpiazu, Basualdo y Khavisse, 1986; Castellani, 2009; Schorr, 2004 y 2012).

${ }^{9}$ La SIGEP fue creada en 1978 mediante la Ley 21.801 bajo la jurisdicción del Ministerio de Economía y con carácter de entidad administrativamente descentralizada. Los objetivos establecidos por la norma de su creación fueron tres: 1) ejercer el control externo de las empresas bajo su órbita, 2) centralizar, homogeneizar y ponderar la información referente a las firmas, 3) asesorar al Ministerio de Economía y demás organismos en aquellos asuntos de su competencia. La SIGEP fue fundada como reemplazo de la Corporación de Empresas Nacionales (CEN), que había sido creada en 1973 como un intento de planificación estatal de largo plazo, de la mano del tercer gobierno peronista. La transición desde la CEN hacia la SIGEP, más allá de la continuidad formal, implicó un cambio sustancial en las funciones del organismo articulador de la actividad de las empresas del Estado a cargo del Ministerio de Economía, ya que se pasó de un modelo de conducción estratégica hacia uno basado en el control externo.
} 
de este artículo de, por ejemplo, las empresas pertenecientes al complejo industrial-militar (Rougier, 2015). ${ }^{10}$

En un primer apartado, se examina el comportamiento de las empresas públicas en materia productiva a partir de los desempeños en términos de producto bruto interno y nivel de actividad. Tal como advierte Boneo, (1980), por el perfil específico de su inserción estructural, el valor agregado de las empresas públicas argentinas tendía al crecimiento en el largo plazo, más allá de los vaivenes en los ciclos políticos. No obstante, muy recurrentemente, frente a los cambios en la orientación política de los gobiernos se producen transformaciones destacables en la composición de ese valor agregado. De allí la relevancia de observar la dinámica del empleo y los indicadores laborales tales como dotación de trabajadores, remuneraciones y productividad laboral, examinados en el segundo apartado. Siguiendo los postulados del autor, cuando el aumento de la producción se da a la par de un incremento en la capacidad productiva del trabajo es considerado un progreso en las capacidades técnico-operativas de las firmas. Por el contrario, cuando el incremento en el volumen físico se produce sobre la base de una mayor intensidad en la explotación de la mano de obra ocurre lo inverso.

La metodología se centra en el análisis estadístico de fuentes secundarias compuestas, fundamentalmente, por balances y publicaciones de la SIGEP. La propuesta del artículo consiste en brindar una mirada de conjunto sobre el desempeño de las firmas que integraron la sindicatura. La heterogeneidad en la cantidad y calidad de información producida por cada una de las empresas dificulta las comparaciones, de modo que la síntesis estadística provista por la SIGEP otorga homogeneidad y coherencia interna a la información disponible. No obstante, también se consultaron los balances de algunas de las firmas en los casos en que se contara con información relevante vinculada al desempeño operativo y laboral de las empresas públicas. Este es el caso de la dotación de personal según categoría profesional para YPF y Gas del Estado. Por último, se recurrió a revistas especializadas de la época con información estadística relevante. ${ }^{11} \mathrm{El}$ criterio para componer la muestra se basó

\footnotetext{
10 También cabe hacer la distinción con formas más amplias de intervención estatal en la actividad empresaria, más allá del control y la propiedad mayoritarios de una firma, las cuáles son analizadas por Belini y Rougier (2008) y Regalsky y Rougier (2015) en torno a la noción de Estado empresario.

${ }^{11}$ El principal sustento estadístico del trabajo es la Síntesis estadística anual de 1983 (SIGEP, 1984), dado que allí se encuentra la última información correspondiente al período bajo análisis e incluye a la mayor parte de los indicadores examinados. No obstante, también se consultaron las síntesis estadísticas previas en caso de algún dato faltante o relevante. Por otro lado, se examinaron publicaciones temáticas de la SIGEP que resultaron pertinentes, como los informes sobre nivel de actividad, series de estudios técnicos o los documentos
} 
en las diez empresas para las que la SIGEP produjo datos de manera continua y exhaustiva, dejando cuatro firmas de lado. ${ }^{12}$ No obstante, se trata de una muestra representativa del total de la sindicatura ya que los casos seleccionados reflejan el 96,4\% de la producción bruta y el 93,6\% de los ingresos por venta del total de la SIGEP (SIGEP, 1983).

\section{Tabla 1 - Empresas públicas de la SIGEP que componen la muestra bajo análisis}

\begin{tabular}{|c|c|c|c|c|}
\hline Combustibles & Energía & Transporte & Comunicaciones & $\begin{array}{l}\text { Industria y } \\
\text { Servicios }\end{array}$ \\
\hline $\begin{array}{c}\text { Yacimientos } \\
\text { Petrolíferos } \\
\text { Fiscales (YPF) }\end{array}$ & Gas del Estado (GE) & $\begin{array}{l}\text { Ferrocarriles } \\
\text { Argentinos } \\
\text { (FA) }\end{array}$ & $\begin{array}{c}\text { Empresa Nacional de } \\
\text { Telecomunicaciones } \\
\text { (ENTEL) }\end{array}$ & $\begin{array}{c}\text { Obras Sanitarias } \\
\text { de la Nación } \\
(\mathrm{OSN})\end{array}$ \\
\hline \multirow[t]{2}{*}{$\begin{array}{c}\text { Yacimientos } \\
\text { Carboníferos } \\
\text { Fiscales (YCF) }\end{array}$} & $\begin{array}{c}\text { Servicios Eléctricos } \\
\text { Gran Buenos Aires } \\
\text { (SEGBA) }\end{array}$ & $\begin{array}{l}\text { Aerolíneas } \\
\text { Argentinas } \\
\text { (AA) }\end{array}$ & $\begin{array}{l}\text { Empresa de Correos y } \\
\text { Telégrafos (ENCOTEL) }\end{array}$ & \\
\hline & $\begin{array}{l}\text { Agua y Energía } \\
\text { Eléctrica (AyEE) }\end{array}$ & & & \\
\hline
\end{tabular}

Fuente: elaboración propia.

Por otra parte, vale la pena mencionar que se trató de firmas muy relevantes dentro de la estructura productiva argentina. Según el ranking de las 200 empresas (públicas y privadas) de mayor facturación publicado por la Revista Prensa Económica, más de la mitad de los casos de la muestra se encontraban entre las primeras diez de la cúpula empresaria nacional entre 1976 y 1983. Se destaca el caso de YPF, que fue la empresa número uno del ranking durante todo el período bajo análisis. ${ }^{13}$ Las restantes también se ubicaron dentro de las 200 firmas con mayor volumen de ventas, aunque en posiciones un poco más relegadas.

En lo relativo al análisis estadístico, para evaluar los saldos de la última

\footnotetext{
de divulgación. El detalle sobre los documentos revisados está en el listado de fuentes hacia final del artículo. Por último, también se consultaron revistas especializadas que proveyeron información estadística valiosa. Este es el caso de la revista Coyuntura y desarrollo de la Fundación de Investigaciones para el Desarrollo (FIDE), que permitió calcular la evolución del salario real según el Índice de Precios al Consumidor y la revista Prensa Económica que publica el ranking de empresas con mayores volúmenes de facturación.

${ }^{12}$ Las cuatro firmas para las que no hay continuidad en la información disponible en la Síntesis Estadística Anual de 1983 de la SIGEP son: Hidroeléctrica Norpatagónica, Empresas de Líneas Marítimas S.A., Flota Fluvial del Estado Argentino y Administración General de Puertos, tres de ellas pertenecientes al sector transporte.

${ }^{13}$ Las otras cinco firmas, además de YPF, que estaban entre las primeras diez fueron GE, SEGBA, ENTEL, AyEE y AA.
} 
dictadura, la comparación entre puntas se efectúa entre 1974 y 1983. Se toma 1974 como año base considerando el criterio consensuado por la tradición intelectual que analizó la economía del autodenominado Proceso de Reorganización Nacional (en adelante, PRN) la cual sostiene que 1974 fue el último año de vigencia plena de la industrialización sustitutiva ${ }^{14}$ (en adelante, ISI) y que 1975 distorsiona mucho la comparabilidad por tratarse de un año con inflación de tres dígitos (Azpiazu et al., 1986; Basualdo, 2010; Castellani, 2004). En las comparaciones entre la ISI y el PRN se tomaron los períodos 1965-1973 y 1974-1983 para contar con categorías mutuamente excluyentes. ${ }^{15}$ En algunos indicadores, como PBI o nivel de actividad, las series disponibles para la comparación hacia atrás sólo llegan hasta el año 1970. En estos casos, por la diferencia en la cantidad de años entre 1970-1973 (ISI) y 1974-1983 (PRN) la comparación entre los modelos se calculó en base a la tasa de variación anual acumulativa.

\section{La dinámica de la producción}

En esta sección se analiza la evolución y los cambios en la composición del Producto Bruto Interno (PBI) de las empresas públicas de la SIGEP. ${ }^{16} \mathrm{Tal}$ como destaca Boneo (1980), los mecanismos por los que puede variar el producto bruto de las empresas públicas resulta de multiplicar la cantidad física por el precio de los bienes y/o servicios producidos, por lo que un incremento en el valor agregado de las mismas puede producirse por tres vías: 1) la incorporación de unidades en el número de firmas que integran la SIGEP vía estatizaciones, 2) el aumento en el volumen fisico producido por las empresas públicas existentes y 3 ) el incremento de los precios de los bienes o servicios producidos por las empresas estatales en relación al resto de la economía considerando que la elasticidad-precio de la demanda de sus productos es menor que uno.

El primer elemento a destacar respecto de la producción bruta de las firmas bajo análisis durante el período dictatorial es que su evolución fue

\footnotetext{
${ }^{14}$ Sobre las características del modelo de industrialización por sustituciones en Argentina y, en particular, el rol desempañado por el Estado empresario remitirse a: Belini y Rougier (2008); Odisio (2018); Regalsky y Rougier, (2015) y Rougier y Odisio, (2019).

${ }^{15}$ Esta decisión metodológica tiende a matizar los resultados de la ISI ya que, como se mencionó previamente, 1974 fue el último año de su vigencia plena.

${ }^{16}$ SIGEP (1988) toma en consideración el PBI a costo de factores en valores constantes a precios de 1970. Estos datos fueron obtenidos del BCRA y actualizados en base a la evolución de distintas series indicativas de los volúmenes fisicos de producción por cada empresa. Para más detalle, ver metodología en SIGEP (1983).
} 
positiva para el conjunto agregado de la SIGEP, también expresado como porcentaje del PBI global, especialmente a partir de 1977. Los años previos al golpe fueron también de crecimiento hasta que, en 1975, se produjo una caída de -2,9\%. En 1976 la caída se frenó con estancamiento, para luego emprender una senda de crecimiento cuyas oscilaciones acompañaron el ritmo del PBI global de la economía. El crecimiento se interrumpió recién en 1981 y 1982, años en los que se produjeron dos caídas consecutivas a la par de la merma en la actividad económica general. No obstante, el PBI de las empresas públicas siempre se mantuvo en niveles más altos de los acontecidos en 1970 tomándolo como índice base. El saldo entre 1974 y 1983 fue un crecimiento de $17,4 \%$ en el PBI de las empresas públicas a costo de factores y un incremento de $16,9 \%$ del PBI de las empresas públicas como porcentaje del PBI global (Tabla 2).

Tal como se anticipó, este crecimiento en el producto bruto generado por las empresas públicas puede deberse a un incremento en la cantidad de empresas que integraron la SIGEP, un aumento en el volumen físico producido por las firmas o un crecimiento de sus precios relativos. Cuando se observa la evolución de los precios y tarifas de las firmas, además de detentar un ritmo sumamente errático, con fluctuaciones pronunciadas en períodos de muy corto plazo, cayeron en términos reales -23,2\% entre 1974 y 1983 (SIGEP,1984). En efecto, el incremento en la producción bruta de las empresas públicas entre 1974 y 1983 no se produjo vía precios sino vía cantidades, a través de un incremento en el volumen físico de su producción. Esto se constata cuando se observa la dinámica del nivel de actividad de las empresas de la SIGEP, ${ }^{17}$ cuya evolución expresa el derrotero del volumen físico producido por las entidades que correlacionó fuertemente con el ritmo de crecimiento del PBI, en marcado contraste con la evolución de los precios y las tarifas. En el Gráfico 1 se observa claramente cómo el volumen físico de la producción (nivel de actividad) y el producto bruto crecieron a la par, mientras que el ritmo de los precios fue sumamente zigzagueante y con tendencia decreciente. El saldo del nivel de actividad para el total de la SIGEP fue

\footnotetext{
${ }^{17}$ En SIGEP (1988) se establece que Nivel de Actividad o Producción Física son considerados sinónimos. Dado que los volúmenes físicos de la producción de las empresas están expresados en unidades diferentes (metros cúbicos, KWh, etc.) o en unidades iguales de distinto valor económico (metros cúbicos de nafta, de gas oil, etc.), a los efectos de obtener un indicador de la producción homogéneo para su agregación, se multiplican dichas unidades por sus precios de 1970. Así se obtiene el Nivel de Actividad, método semejante al cálculo delValor de la Producción y el Producto Global de la economía. Para más detalle ver SIGEP (1980).
} 
Tabla 2 - Producto Bruto Interno de las empresas públicas. A costo de factores. Valores constantes. Datos anuales $(1970-1983) \star$

\begin{tabular}{c|c|c|c|c}
\hline Año & $\begin{array}{c}\text { Como \% del } \\
\text { PBI global }\end{array}$ & $\begin{array}{c}\text { En millones de } \\
\mathbf{\$} \text { de } \mathbf{1 9 7 0}\end{array}$ & $\begin{array}{c}\text { Índice base } \\
\mathbf{1 9 7 0 = 1 0 0}\end{array}$ & $\begin{array}{c}\text { Variación } \\
\text { Interanual \% }\end{array}$ \\
\hline 1970 & 7,0 & 5415,6 & 100,0 & \\
\hline 1971 & 7,2 & 5790,7 & 106,9 & 6,9 \\
\hline 1972 & 7,3 & 6015,3 & 111,1 & 3,9 \\
\hline 1973 & 7,4 & 6253,6 & 115,5 & 4,0 \\
\hline 1974 & 7,1 & 6342,5 & 117,1 & 1,4 \\
\hline 1975 & 6,9 & 6161,5 & 113,8 & $-2,9$ \\
\hline 1976 & 6,9 & 6167,9 & 113,9 & 0,1 \\
\hline 1977 & 6,8 & 6497,6 & 120,0 & 5,3 \\
\hline 1978 & 7,3 & 6712,4 & 123,9 & 3,3 \\
\hline 1979 & 7,6 & 7451,7 & 137,6 & 11,0 \\
\hline 1980 & 7,7 & 7591,1 & 140,2 & 1,9 \\
\hline 1981 & 7,9 & 7314,3 & 135,1 & $-3,6$ \\
\hline 1982 & 8,3 & 7212,2 & 133,2 & $-1,4$ \\
\hline 1983 & 8,3 & 7447,7 & 137,5 & 3,3 \\
\hline $\mathbf{1 9 8 3 / 1 9 7 4}$ & $\mathbf{1 6 , 9}$ & & $\mathbf{1 7 , 4}$ & \\
\hline \multirow{2}{*}{$\mathbf{1 9}$} & & & & \\
\hline
\end{tabular}

* Para reconstruir la evolución del Producto Bruto Interno de las Empresas Públicas se recurrió a dos fuentes de la SIGEP que mostraron algunas discrepancias que se detallan a continuación. El porcentaje de PBI de las empresas públicas como porcentaje del PBI Global se extrajo de la Serie de divulgación $\mathrm{N}^{\circ} 12$ publicada en 1985. Allí también consta la evolución del PBI a precios constantes con índice base 1970, pero varía ligeramente de los valores expresados en la Síntesis Estadística Anual de 1983, publicada en 1984. Se optó por tomar los datos de la segunda fuente mencionada, dada la mayor rigurosidad que acredita que se encuentren detallados los millones de pesos de 1970, sobre los que se calculó la variación del índice base 1970=100. De todas maneras, la variación entre una fuente y otra no supera los cinco decimales en ninguno de los años bajo análisis, por lo tanto, no afecta el sentido general del análisis efectuado.

Fuente: elaboración propia en base a $\operatorname{SIGEP}(1984$, p. 9) y $\operatorname{SIGEP}(1985$, p.6).

$24,4 \%$ de incremento entre 1974 y $1983 .{ }^{18}$ En cuanto a la posible injerencia de nuevas empresas públicas en la generación de valor agregado, es dable recordar que en 1979 se produjo la estatización de la Compañía Ítalo-Argentina de Electricidad que se incorporó íntegramente a SEGBA. Este movimiento pudo contribuir a explicar el incremento especialmente destacado que se produjo en 1979, sumado a que fue un año de gran crecimiento de

\footnotetext{
${ }^{18}$ El cálculo se efectuó en base a la información disponible en SIGEP (1984, p. 8).
} 
la actividad económica general. No obstante, el impacto de este fenómeno es leve, ya que en 1978 SEGBA representaba el 10,3\% del total del producto bruto de las empresas de la SIGEP, en 1979 pasó a representar el 12\% y en 1980 retrocedió a 10,9\%. En suma, el grueso de la evolución del PBI se explica por el incremento en la producción fisica en las empresas que ya integraban la sindicatura (SIGEP, 1984).

\section{Gráfico 1 - Nivel de actividad, producto bruto interno y precios} y tarifas del total de empresas públicas de la SIGEP (1970-1983)

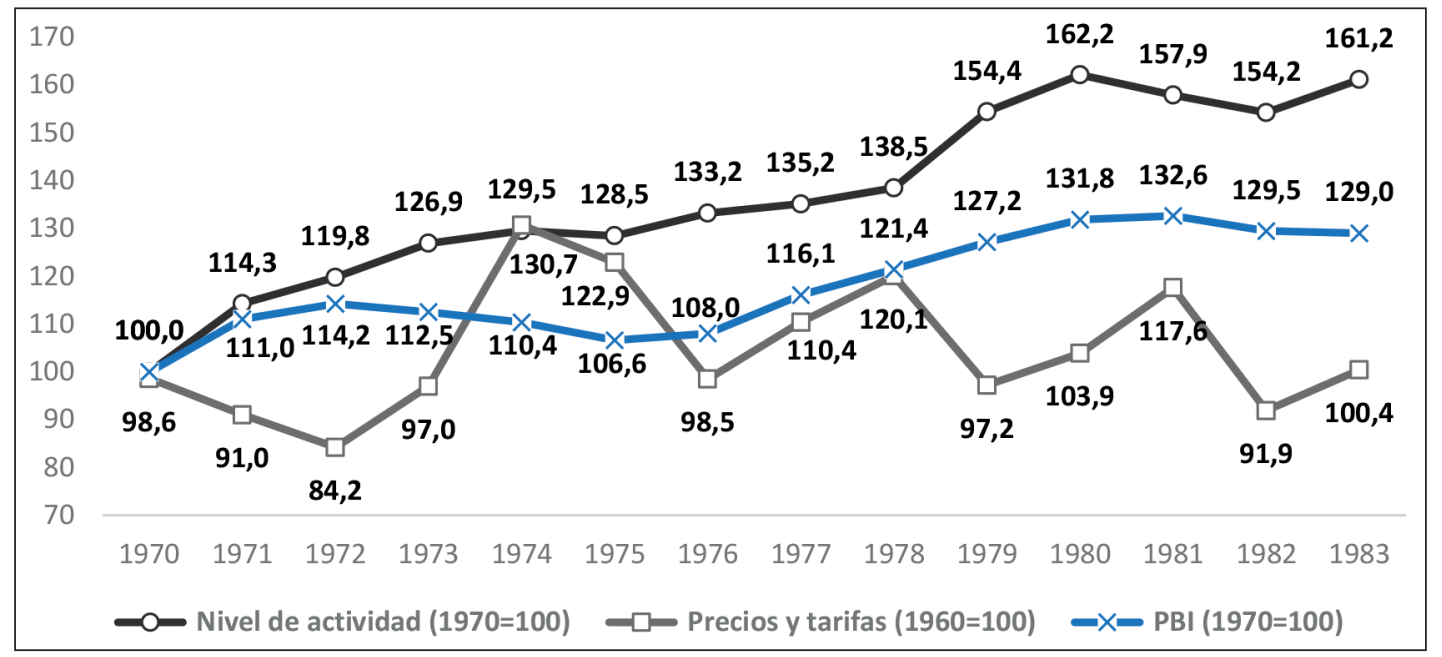

Fuente: elaboración propia en base a SIGEP (1984), pp. 7, 9 y 10.

Como se anticipó, varias razones vinculadas al perfil específico de inserción de las empresas públicas en la estructura productiva argentina permiten suponer una tendencia al incremento en el largo plazo del valor agregado por las entidades. Boneo (1980) señaló dos de las más relevantes. Primero, la tarea de privatización no fue sencilla aún en los gobiernos de fuerte vocación liberal y antiestatista, dado que no fue fácil encontrar compradores en el sector privado y porque, incluso al interior de esta gestión de carácter autoritario, se registran resistencias por parte de diversos grupos. Segundo, algunos de los sectores más dinámicos (petróleo, energía eléctrica, siderurgia, etc.) estuvieron casi íntegramente bajo gestión estatal. Al crecer más rápidamente que el conjunto de la economía, aumentaron necesariamente la proporción estatal del valor agregado. A continuación, se analiza cómo esas ventajas del perfil de inserción de las empresas estatales fueron transferidas vía precios y tarifas regazadas al sector privado.

A pesar de estar centrados en las transformaciones operadas en el sector privado industrial, algunos trabajos advirtieron el desacople entre el volumen 


\section{Gráfico 2 - PBI de las empresas públicas. Tasa de variación anual acumulativa 1970-1973 (ISI) y 1974-1983 (PRN)}

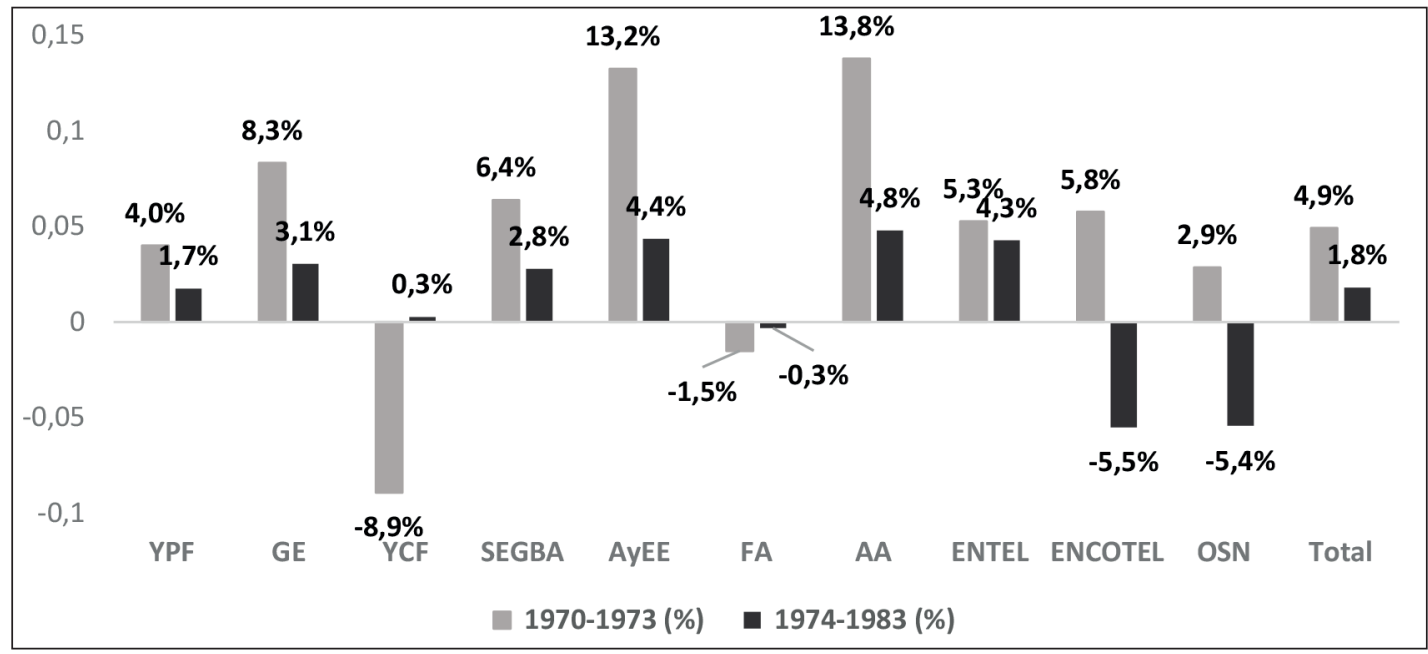

Fuente: elaboración propia en base a SIGEP (1984).

físico producido por las empresas públicas y los precios de venta. Azpiazu, Basualdo y Khavisse (1986) identificaron a las empresas del Estado como parte de los tres tipos de entidades que aumentaron su participación en la producción industrial, junto con los grupos económicos locales y las empresas transnacionales diversificadas y/o integradas, cuando se mide solamente el volumen físico. No obstante, si se considera la producción a precios corrientes, se produce una declinación de la participación de las empresas públicas y un incremento aún mayor en los grupos económicos y las empresas transnacionales. Para los autores, este proceso implicó una creciente transferencia de ingresos desde el Estado hacia el capital concentrado interno a partir de un incremento en el volumen físico de la producción acompañado por una caída en sus precios relativos. En efecto, esta hipótesis se corrobora en base a los indicadores por empresa, como puede visualizarse en el Gráfico 2, que describe la tasa de variación anual acumulativa (en adelante,TVAA) del PBI de las firmas. En la mayor parte de los casos hubo una evolución positiva en términos del producto bruto interno entre 1974 y 1983 con tres excepciones (FA, ENCOTEL y OSN) aunque el crecimiento fue más moderado que durante la industrialización sustitutiva. Entre 1970 y 1973 la TVAA para el total de la SIGEP fue 4,9\%, mientras que entre 1974 y 1983 fue 1,8\%. El caso de FA es particular, porque su desempeño fue muy negativo en varios indicadores, también durante la industrialización sustitutiva. De hecho, la TVAA de FA entre 1970 y 1983 fue -1,5\% y entre 1974 y 1983 redujo la intensidad de su caída a -0,3\%. Los casos de ENCOTEL y OSN fueron los que más pérdida arrojaron entre 1974 y $1983,-5,5 \%$ y $-5,4 \%$, respectivamente. 
El resto de las entidades bajo análisis tuvo un desempeño positivo en su producción bruta entre 1974 y 1983, aunque con diferentes magnitudes. Las tres empresas que más incrementaron su producción fueron, en primer lugar, AA con un incremento entre puntas 4,8\% en la TVAA y, en segundo lugar, AyEE con un aumento de 4,4\%. En tercer lugar, se ubica ENTEL con un incremento de 4,3\%. Luego, se suman GE con un incremento entre puntas de $3,1 \%$, SEGBA con un incremento 2,8\% e YPF con 1,7\% de crecimiento entre puntas. Por último, YCF mostró una suba mucho más moderada de su producción bruta en sólo 0,3\% entre 1974 y 1983.

En términos de los sectores y subsectores de actividad, hacia 1983 se identifica un crecimiento en el porcentaje del total representado por el sector combustibles y energía y un decrecimiento de los sectores transporte y comunicaciones e industria y servicios. El crecimiento del primero se explica, fundamentalmente, por un incremento en el subsector energía (SEGBA y AyEE) mientras que el subsector combustible (YPF, GE eYCF) se mantuvo relativamente estable. Ahora bien, en cuanto a las empresas que integran los subsectores, tanto AyEE como GE ampliaron su representación sobre el total, mientras que YCF, YPF y SEGBA se mantuvieron relativamente estables. En cambio, el sector transporte y comunicaciones perdió representación sobre el total del PBI de las empresas públicas al igual que industria y servicios. En transporte y comunicaciones la reducción operó, sobre todo, en el subsector transporte, aunque la empresa que perdió porcentaje de representación sobre el PBI total fue FA, mientras que AA creció en representación. En cuanto al sector comunicaciones, se mantuvo estable, pero en la mirada por empresa ENTEL mejora su posición mientras que ENCOTEL empeora. Por último, en industria y servicios se encuentra incluida solamente OSN, empresa que redujo casi a la mitad su participación sobre el total del PBI de las empresas de la SIGEP (Tabla 3).

Tabla 3 - Porcentaje del PBI total de las empresas de la SIGEP según sector y subsector de actividad (1970-1983)

\begin{tabular}{l|l|l|l|l|l|l|l|l|l|l|l|l|l|l}
\hline $\begin{array}{c}\text { Sector y } \\
\text { subsector de } \\
\text { actividad }\end{array}$ & $\mathbf{1 9 7 0}$ & $\mathbf{1 9 7 1}$ & $\mathbf{1 9 7 2}$ & $\mathbf{1 9 7 3}$ & $\mathbf{1 9 7 4}$ & $\mathbf{1 9 7 5}$ & $\mathbf{1 9 7 6}$ & $\mathbf{1 9 7 7}$ & $\mathbf{1 9 7 8}$ & $\mathbf{1 9 7 9}$ & $\mathbf{1 9 8 0}$ & $\mathbf{1 9 8 1}$ & $\mathbf{1 9 8 2}$ & $\mathbf{1 9 8 3}$ \\
\hline $\begin{array}{l}\text { Combustible y } \\
\text { energía }\end{array}$ & 55,9 & 58,3 & 58,7 & 57,5 & 56,4 & 57,6 & 58,8 & 60,4 & 61,1 & 61,8 & 61,7 & 62,9 & 61,9 & 59,9 \\
\hline Combustible & 40,4 & 41,9 & 41,8 & 40,0 & 39,5 & 39,6 & 40,5 & 40,5 & 40,7 & 38,8 & 39,4 & 41,2 & 41,0 & 40,2 \\
\hline Energía & 15,5 & 16,4 & 16,9 & 17,5 & 16,9 & 18,0 & 18,3 & 19,9 & 20,4 & 23,0 & 22,3 & 21,7 & 20,9 & 19,8 \\
\hline
\end{tabular}


Tabla 3 - Porcentaje del PBI total de las empresas de la SIGEP según sector y subsector de actividad (1970-1983)

\begin{tabular}{l|l|l|l|l|l|l|l|l|l|l|l|l|l|l}
\hline $\begin{array}{c}\text { Sector y } \\
\text { subsector de } \\
\text { actividad }\end{array}$ & $\mathbf{1 9 7 0}$ & $\mathbf{1 9 7 1}$ & $\mathbf{1 9 7 2}$ & $\mathbf{1 9 7 3}$ & $\mathbf{1 9 7 4}$ & $\mathbf{1 9 7 5}$ & $\mathbf{1 9 7 6}$ & $\mathbf{1 9 7 7}$ & $\mathbf{1 9 7 8}$ & $\mathbf{1 9 7 9}$ & $\mathbf{1 9 8 0}$ & $\mathbf{1 9 8 1}$ & $\mathbf{1 9 8 2}$ & $\mathbf{1 9 8 3}$ \\
\hline $\begin{array}{l}\text { Transporte y } \\
\text { comunicaciones }\end{array}$ & 41,2 & 38,9 & 38,6 & 39,7 & 40,8 & 39,4 & 38,1 & 36,6 & 36,1 & 35,6 & 36,8 & 35,6 & 36,6 & 38,6 \\
\hline Transporte & 23,7 & 21,8 & 21,4 & 22,0 & 23,0 & 22,8 & 22,4 & 21,3 & 20,7 & 21,1 & 21,3 & 19,4 & 19,1 & 20,7 \\
\hline Comunicaciones & 17,4 & 17,1 & 17,2 & 17,7 & 17,8 & 16,6 & 15,8 & 15,3 & 15,4 & 14,4 & 15,5 & 16,2 & 17,5 & 17,9 \\
\hline $\begin{array}{l}\text { Industria y } \\
\text { Servicios }\end{array}$ & 2,9 & 2,8 & 2,8 & 2,8 & 2,8 & 3,1 & 3,1 & 3,0 & 2,9 & 2,6 & 1,5 & 1,5 & 1,5 & 1,5 \\
\hline Total & $\mathbf{1 0 0}$ & $\mathbf{1 0 0}$ & $\mathbf{1 0 0}$ & $\mathbf{1 0 0}$ & $\mathbf{1 0 0}$ & $\mathbf{1 0 0}$ & $\mathbf{1 0 0}$ & $\mathbf{1 0 0}$ & $\mathbf{1 0 0}$ & $\mathbf{1 0 0}$ & $\mathbf{1 0 0}$ & $\mathbf{1 0 0}$ & $\mathbf{1 0 0}$ & $\mathbf{1 0 0}$ \\
\hline
\end{tabular}

Fuente: elaboración propia en base a SIGEP (1984, p. 9).

Este camino de crecimiento asumido por la producción contrasta notablemente con la dinámica asumida por el empleo, tanto en términos de ocupación como en la evolución de las remuneraciones en el ámbito de las empresas públicas. En efecto, la dinámica laboral que se instala a partir de 1976 estuvo signada por una expulsión ininterrumpida de la mano de obra y un deterioro notable de los salarios reales, erosionando las capacidades técnico-operativas de las firmas.

\section{La "racionalización" de los planteles laborales}

A lo largo de casi todo el período bajo consideración se produjo un descenso significativo de la ocupación en el sector público nacional, quebrando la tendencia alcista que se había consolidado desde los inicios de la década de 1970. Martínez de Hoz lo anunció como objetivo central de la política económica en su discurso programático del 2 de abril de 1976, en el marco del denominado principio de subsidiariedad estatal, que pregonaba la necesidad de reducir drásticamente el papel del Estado en la economía. Durante el primer año de gestión, el gobierno de facto sancionó una serie de normas que afectaron la estabilidad del empleo público. El mismo día de asunción, el 24 de marzo de 1976, se promulgó la Ley 21.260 que autorizaba a los distintos poderes del Estado a dar de baja "por razones de seguridad" aquellos trabajadores estatales que estuvieran vinculados a "actividades de carácter subversivo disociadoras". A los pocos días, el 29 de marzo de 1976 se sancionó la Ley 21.274, que impulsó el denominado "régimen de pres- 
cindibilidad" de los trabajadores estatales, en el cual se contemplaba la eliminación del derecho a indemnización para aquellos agentes que real o potencialmente constituyeran un "factor de perturbación del normal funcionamiento" de la institución pública que integrasen ${ }^{19}$ (Iramain, 2014).

Tal como se observa en la Tabla 4, la caída del empleo en el sector público nacional fue de -13,6\% entre 1974 y 1983, lo que implicó un constreñimiento de los planteles laborales de -122.876 agentes. Ahora bien, el proceso de "racionalización" ${ }^{20}$ para las empresas bajo la órbita de la SIGEP fue aún más intenso: mientras en 1974 las firmas de la sindicatura ocuparon 393.942 agentes, en 1983 la dotación de personal se redujo a 301.043 lo que implicó una reducción de -92.899 en la cantidad trabajadores. Es decir, que se produjo una caída del $-23,6 \%$ en la ocupación del total de las empresas de la SIGEP. ${ }^{21}$ En cuanto a la evolución interanual, para el total de empresas el deterioro fue ininterrumpido desde 1976, con las caídas interanuales más importantes en 1977, 1978 y 1980. La gestión de Martínez de Hoz concentró la mayor parte de la reducción de los planteles laborales, pero la tendencia decreciente se mantuvo constante hasta 1983.

\section{Tabla 4 - Ocupación del Sector Público Nacional (SPN) y del total de empresas de la SIGEP. Cantidad de agentes, índice base} $1974=100$ y $\%$

\begin{tabular}{c|c|c|c|c|c}
\hline Años & $\begin{array}{c}\text { Cantidad } \\
\text { de agentes } \\
\text { en el SPN }\end{array}$ & $\begin{array}{c}\text { SPN } \\
\text { Índice base } \\
\mathbf{1 9 7 4}=\mathbf{1 0 0}\end{array}$ & $\begin{array}{c}\text { Cantidad } \\
\text { de agentes } \\
\text { SIGEP }\end{array}$ & $\begin{array}{c}\text { SIGEP } \\
\text { Índice base } \\
\mathbf{1 9 7 4 = 1 0 0}\end{array}$ & $\begin{array}{c}\text { Var. i.a. } \\
\text { SIGEP (\%) }\end{array}$ \\
\hline 1974 & 890.929 & 100 & 393.942 & 100,0 & 2,3 \\
\hline
\end{tabular}

\footnotetext{
${ }^{19}$ El contenido entre comillas es original del autor Iramain, (2014).

${ }^{20}$ El término fue el empleado por los representantes de la gestión económica para referirse a la contundente reducción de los planteles laborales aplicada en el sector público.

21 Tal como se aclaró en la introducción, existe un amplio consenso en la literatura especializada que establece el año 1974 como base para calcular los saldos del PRN. No obstante, lo relativo a la dotación de trabajadores puede despertar especial inquietud, por la sensibilidad a los cambios políticos de un indicador vinculado al empleo púbico; así como por la centralidad que tiene en el análisis de este artículo, que plantea la emergencia de un cambio cualitativo en la relación producción-empleo. Cuando se observa la cantidad de trabajadores de la SIGEP para el año 1974 (393.942 agentes) se ubica en niveles similares al promedio de la cantidad de trabajadores entre 1966-1975 (387.231 agentes). Más aún, el año en que se dispara de manera excepcional el empleo de la SIGEP es 1975, cuando incrementa su dotación de trabajadores a 424.923 agentes (el aumento interanual de 1973 fue 2,9\%, el de 1974 fue 2,3\% y el de 1975 fue 7,9\%). Es decir, que tomando 1974 como año base se encubre ese aumento coyuntural, matizando los resultados de la ISI y robusteciendo la interpretación que se ofrece en este artículo. Si se examina el largo plazo, en comparación con la ISI, la racionalización de los planteles laborales de la SIGEP durante la última dictadura argentina tuvo características de cambio estructural.
} 
Tabla 4 - Ocupación del Sector Público Nacional (SPN) y del total de empresas de la SIGEP. Cantidad de agentes, índice base $1974=100$ y $\%$

\begin{tabular}{c|c|c|c|c|c}
\hline Años & $\begin{array}{c}\text { Cantidad } \\
\text { de agentes } \\
\text { en el SPN }\end{array}$ & $\begin{array}{c}\text { SPN } \\
\text { Índice base } \\
\mathbf{1 9 7 4}=\mathbf{1 0 0}\end{array}$ & $\begin{array}{c}\text { Cantidad } \\
\text { de agentes } \\
\text { SIGEP }\end{array}$ & $\begin{array}{c}\text { SIGEP } \\
\text { Índice base } \\
\mathbf{1 9 7 4 = 1 0 0}\end{array}$ & $\begin{array}{c}\text { Var. i.a. } \\
\text { SIGEP (\%) }\end{array}$ \\
\hline 1975 & 950.160 & 106,6 & 424.923 & 107,9 & 7,9 \\
\hline 1976 & 951.195 & 106,8 & 419.371 & 106,5 & $-1,3$ \\
\hline 1977 & 934.493 & 104,9 & 373.472 & 94,8 & $-10,9$ \\
\hline 1978 & 857.646 & 96,3 & 344.478 & 87,4 & $-7,8$ \\
\hline 1979 & 782.094 & 87,8 & 332.594 & 84,4 & $-3,4$ \\
\hline 1980 & 762.751 & 85,6 & 309.554 & 78,6 & $-6,9$ \\
\hline 1981 & 745.045 & 83,6 & 296.623 & 75,3 & $-4,2$ \\
\hline 1982 & 747.431 & 83,9 & 288.828 & 73,3 & $-2,6$ \\
\hline 1983 & 768.053 & 86,2 & 301.043 & 76,4 & 4,2 \\
\hline $\mathbf{1 9 7 4 - 1 9 8 3}$ & $\mathbf{- 1 2 2 . 8 7 6}$ & $\mathbf{- 1 3 , 8}$ & $\mathbf{- 9 2 . 8 9 9}$ & $\mathbf{- 2 3 , 6}$ & \\
\hline
\end{tabular}

Fuente: elaboración propia en base a Ferreres (2010, p.558) para la ocupación del SPN y SIGEP (1984, p. 18-19).

Gráfico 3 - Ocupación de las empresas públicas. Variación porcentual 1966-1973 y 1974-1983. Variación en la cantidad de agentes 1974-1983 (recuadro rojo)

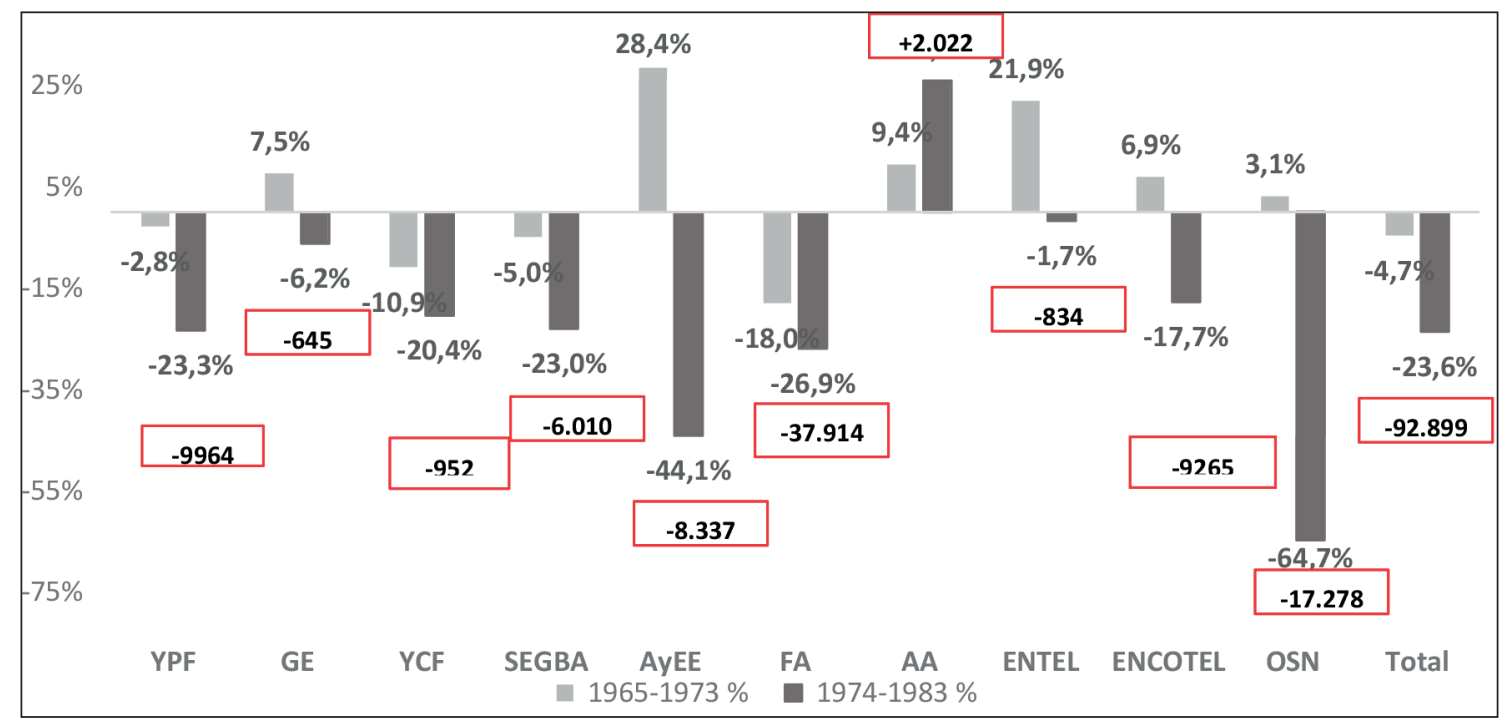

Fuente: elaboración propia en base a SIGEP (1984, p. 18-19). 
Cuando se analiza la evolución de la dotación de personal por empresa, la caída en la cantidad de agentes operó en todos los casos con excepción de AA, cuya evolución entre 1974 y 1983 implicó un incremento de 25,9\%, incorporando 2.022 nuevos agentes. Los casos de caídas más bajas en términos de dotación de personal fueron ENTEL, con una caída de -1,7\% que implicó -834 menos entre 1974 y 1983 y GE, cuya merma entre puntas fue de $-6,2 \%$, lo que representó una caída mucho más baja en términos de la cantidad de agentes, de sólo -645 casos por tratarse de una entidad con baja densidad de trabajadores. La mayor parte de las empresas evidenciaron caídas cercanas al -20\%.YPF detentó una reducción de $-23,3 \%$ entre puntas lo que implicó -9.964 agentes menos, YCF redujo su personal en -20,4\% lo que conllevó una reducción mucho más atenuada en cantidades, de -952 agentes menos. En el caso de SEGBA la caída porcentual entre puntas fue de $-23 \%$, lo que equivalió a -6010 agentes menos. En FA la pérdida entre puntas fue de $-26,9 \%$ y la magnitud de la reducción en cantidad de agentes fue particularmente destacada en valores absolutos, con -37914 agentes menos, por la gran densidad de trabajadores que integraron la compañía. Por su parte, ENCOTEL detentó una caída de -17,7\% entre puntas lo que implicó -9.265 agentes para la empresa de correos y telégrafos (Gráfico 3).

Los casos más acentuados en términos de reducción de los planteles laborales fueron AyEE, y OSN que cayeron -44,1\% y -64,7\% entre 1974 y 1983 respectivamente. Ambas fueron las más afectadas por una situación particular, ya que gran parte de la caída en la cantidad de agentes se explica por la transferencia de la prestación de los servicios esenciales desde el Estado nacional hacia las provincias y la absorción por parte de éstas del personal desafectado, en muchos casos sin las correspondientes transferencias de las partidas presupuestarias (Aronskind, 2001, 2008). Esto operó en el marco de la privatización periférica ${ }^{22}$ y los procesos de descentralización y "provincialización" de ciertos servicios básicos. No obstante, más allá del traspaso del servicio hacia las jurisdicciones provinciales, no deja de ser destacable la magnitud de la caída en comparación con las ya de por sí significativas disminuciones de los planteles de las restantes empresas públicas analizadas,

\footnotetext{
${ }^{22}$ La privatización periférica, basada en el traspaso a capitales privados de actividades relevantes realizadas hasta el momento por las grandes empresas públicas, fue caracterizada por varios autores como una suerte de privatización parcial o anticipada. Eso se había puesto en práctica con anterioridad (subcontratación de actividades por razones diversas), pero la novedad del período fue la presión que se ejercía por parte del ejecutivo para que se transfieran la mayor cantidad de actividades posibles y la relevancia de las mismas (Iramain, 2015; Schvarzer, 1981).
} 
muchas de ellas también afectadas por la "provincialización"y con reducciones de personal mucho más moderadas como GE o ENTEL. En AyEE la caída de la dotación alcanzó los -8.337 puestos de trabajo mientras que para OSN la reducción fue de -17.278 durante ese lapso (Gráfico 3).

Durante los últimos años de la industrialización sustitutiva (1966-1973), seis de las diez empresas bajo análisis incrementaron su dotación de trabajadores (GE, AyEE, AA, ENTEL, ENCOTEL y OSN) y cuatro de ellas la redujeron (YPF, YCF, SEGBA y FA). También para el total de empresas de la SIGEP representa una baja, ya que entre 1965 y 1973 la dotación de trabajadores de las empresas públicas se redujo $-4,7 \%$. Ahora bien, la novedad de la última dictadura militar radica en la generalidad y magnitud del fenómeno. Todas las empresas, con excepción de AA, redujeron la cantidad de agentes y en magnitudes mucho más importantes que en los nueve años previos (Gráfico 3).

En suma, a partir del golpe de Estado de 1976 se produjo un menoscabo muy importante en la dotación de los planteles laborales de las empresas públicas, tanto por la magnitud de la caída como por la generalidad con la que se llevó a cabo el fenómeno. Si bien durante la industrialización sustitutiva algunas empresas públicas tuvieron caídas en la cantidad de agentes y en el nivel general se redujo $-4,7 \%$ la dotación de trabajadores entre 1965 y 1973, a partir de la última dictadura militar se abrió un proceso ininterrumpido (todos los años hubo reducción en la cantidad de trabajadores de la SIGEP) y de gran magnitud, dado que hacia el final del PRN la SIGEP había reducido un cuarto de su personal. En cuanto al análisis por empresa, puede decirse que la caída en la ocupación fue generalizada, con un solo caso, el de AA, que aumentó la dotación de trabajadores. No obstante, hubo una heterogeneidad destacable en lo relativo a la magnitud de esas reducciones. ENTEL y GE tuvieron descensos de personal muy moderados, si se tiene en cuenta, además, que fueron afectadas por la descentralización de sus actividades en el marco de la privatización periférica. La mayor parte de las empresas achicó sus planteles cerca del 20\%. En términos absolutos, algunas empresas se vieron más afectadas ya que incorporaban gran cantidad de trabajadores, como el caso deYPF, que si bien su variación entre puntas fue del -23,3\% implicó en los hechos una pérdida de -9.964 agentes. Por último, AyEE y OSN fueron las empresas cuya caída en la variación porcentual de los planteles fue más pronunciada. En cuanto a la evolución interanual, la caída en la dotación fue ininterrumpida hasta 1983, con especial intensidad entre 1977 y 1980 bajo la gestión de Martínez Hoz. El ritmo de la reducción de personal no 
siguió necesariamente el mismo derrotero empresa por empresa, o en sus respectivos sectores o subsectores de actividad.

Por otra parte, la reducción del personal ocupado en las empresas públicas no se dio de igual manera en todos los niveles de calificación, sino que tuvo mayor intensidad en el personal obrero, técnico y de menor calificación. El propósito explícito de la Sindicatura radicaba en dirigirse hacia la "jerarquización" de los puestos de trabajo y retener al personal más calificado (Castellani y Iramain, 2015). Sobre este tipo de información no se obtuvieron datos para el total de la SIGEP. No obstante, para ilustrar el fenómeno se recurrió a los balances de dos de las firmas más importantes que disponían de dicha aclaración en sus registros:YPF y GE. Cuando se observa la evolución del personal ocupado de GE según nivel de calificación, se constata que el personal obrero, de servicio, especializado y rector es el que más pérdida manifestó durante el período, con una variación entre 1974 y 1983 de -27,9\%. El resto de las categorías incrementó el personal ocupado, aunque con menor intensidad en el personal administrativo y técnico y con mayor intensidad en el personal superior, profesionales del arte de curar y personal de aviación contratado, becarios, etc. Aquí se observa un sesgo hacia el incremento del personal más calificado y jerárquico, junto con un aumento de la precarización laboral, por lo que implica la modalidad de contratos o becas. En el caso de YPF se evidencia la misma tendencia. La única categoría dentro del personal ocupado que crece entre 1975 y 1983 es la de profesionales, mientras que técnicos, administrativos y maestranzas reducen fuertemente la cantidad de agentes, con más intensidad en estas dos últimas categorías. Cabe mencionar que la variación entre puntas para el total de GE y YPF discrepa levemente de la evolución remitida en el análisis del apartado anterior, debido a que difieren los datos de los balances de la SIGEP y los propios registros de cada una de las firmas. Pero más allá de este desfasaje en los registros, se consideró pertinente mostrar el sesgo en cuanto a nivel de calificación en la caída del personal ocupado ${ }^{23}$ (Tabla 5).

\footnotetext{
${ }^{23}$ En el caso de GE del Estado la discrepancia se encuentra en la cantidad de agentes "de origen”. Según el balance de la SIGEP, GE tenía 10.436 agentes en 1974, pero en el boletín estadístico anual de 1984 publicado por la propia GE la cantidad de agentes en 1974 era de 10.168. No obstante, ambas fuentes coinciden en que en 1983 el personal ocupado de la empresa correspondía a 9.791 trabajadores. De aquí la discrepancia en las variaciones porcentuales entre 1974 y 1983, que en un caso es de $-1,7 \%$ y en otro de -3,7\%. En el caso de YPF, no hay diferencias en los datos, sino que en el Anuario Estadístico de 1983 la entidad comenzó a contabilizar desde 1975, lo que no habilita la comparación con 1974.
} 
Tabla 5 - Evolución de la dotación de personal de Gas del Estado por categoría profesional 1974-1983 (índice base 1974=100)

\begin{tabular}{c|c|c|c|c|c|c}
\hline $\mathbf{A n ̃ o s}$ & $\begin{array}{c}\text { Personal } \\
\text { obrero, de } \\
\text { servicio, } \\
\text { especializado } \\
\text { y rector }\end{array}$ & $\begin{array}{c}\text { Personal } \\
\text { administrativo, } \\
\text { técnico, } \\
\text { profesional y } \\
\text { rector }\end{array}$ & Personal & Superior & $\begin{array}{c}\text { Personal } \\
\text { de } \\
\text { Profesionales } \\
\text { del arte de } \\
\text { curar } \\
\text { aviación, } \\
\text { contratado, } \\
\text { becarios, } \\
\text { etc. }\end{array}$ & $\begin{array}{c}\text { Total } \\
\text { de } \\
\text { agentes }\end{array}$ \\
\hline 1974 & 100,0 & 100,0 & 100,0 & 100,0 & 100,0 & 100,0 \\
\hline 1975 & 94,6 & 112,8 & 100,0 & 98,4 & 37,5 & 103,4 \\
\hline 1976 & 90,9 & 111,9 & 96,4 & 139,8 & 171,9 & 102,0 \\
\hline 1977 & 86,6 & 108,7 & 121,8 & 134,1 & 56,3 & 98,7 \\
\hline 1978 & 83,4 & 110,2 & 119,6 & 133,3 & 193,8 & 98,2 \\
\hline 1979 & 83,0 & 118,3 & 124,4 & 142,3 & 84,4 & 101,8 \\
\hline 1980 & 81,2 & 121,6 & 120,7 & 139,8 & 93,8 & 102,4 \\
\hline 1981 & $\mathbf{7 7 , 6}$ & 119,8 & 139,3 & 142,3 & 153,1 & 100,6 \\
\hline 1982 & $\mathbf{7 2 , 3}$ & 112,8 & 159,3 & 137,4 & 165,6 & 95,2 \\
\hline 1983 & $\mathbf{7 2 , 1}$ & 114,8 & 155,6 & 154,5 & 196,9 & 96,3 \\
\hline $\mathbf{1 9 8 3 / 1 9 7 4}$ & $\mathbf{- 2 7 , 9}$ & $\mathbf{1 4 , 8}$ & $\mathbf{5 5 , 6}$ & $\mathbf{5 4 , 5}$ & $\mathbf{9 6 , 9}$ & $\mathbf{- 3 , 7}$ \\
\hline
\end{tabular}

Fuente: elaboración propia en base a Gas del Estado (1984, p. 134).

Tabla 6 - Evolución de la dotación de personal de YPF por categoría profesional 1975-1983 (índice base 1974=100)

\begin{tabular}{c|c|c|c|c|c}
\hline Años & Profesionales & Técnicos & Administrativos & Maestranzas & Total de agentes \\
\hline 1975 & 100,0 & 100,0 & 100,0 & 100,0 & 100,0 \\
\hline 1976 & 100,1 & 106,0 & 102,5 & 92,6 & 96,5 \\
\hline 1977 & 91,4 & 95,2 & 89,2 & 82,8 & 86,0 \\
\hline 1978 & 94,2 & 84,9 & 74,7 & 70,6 & 74,4 \\
\hline 1979 & 101,8 & 87,2 & 76,1 & 62,7 & 70,3 \\
\hline 1980 & 112,9 & 94,3 & 59,6 & 58,6 & 66,5 \\
\hline 1981 & 130,3 & 88,9 & 52,5 & 56,2 & 63,8 \\
\hline 1982 & 134,0 & 87,3 & 51,0 & 53,9 & 62,0 \\
\hline 1983 & 142,8 & 91,5 & 52,1 & 56,4 & 64,8 \\
\hline $\mathbf{1 9 7 5 - 1 9 8 3}$ & $\mathbf{4 2 , 8}$ & $\mathbf{- 8 , 5}$ & $\mathbf{- 4 7 , 9}$ & $\mathbf{- 4 3 , 6}$ & $\mathbf{- 3 5 , 2}$ \\
\hline
\end{tabular}

Fuente: elaboración propia en base a datos de YPF (s/f), Anuario Estadístico 1983, p. 154; YPF (s/f), Anuario Estadístico 1982, p. 144;YPF (s/f), Anuario Estadístico 1978, p. 140. 


\section{Los salarios como costo laboral y como poder adquisitivo}

En este escenario de transformaciones regresivas del empleo, el nivel del salario en las empresas públicas cumplió un rol fundamental, en base a su notable deterioro. En este apartado se describe, primero, la evolución del salario real medido como costo laboral; es decir, el salario real bruto medio de las empresas públicas deflactado por el Índice de Precio Mayoristas No Agropecuarios (IPMNA). Se opta inicialmente por ésta lectura, dado que permite evaluar el derrotero del salario en función de las capacidades técnico-operativas de las firmas. No obstante, se agrega luego la lectura del salario real entendido como poder adquisitivo de sus trabajadores; es decir, el salario real bruto medio deflactado por el Índice de Precios al Consumidor (IPC), para dimensionar la magnitud de la crisis en el mercado de trabajo, más allá de los costos de las firmas. ${ }^{24}$ De esta forma, se analizan los cambios en el nivel del salario real desde los dos lados del mostrador: como costo laboral para las empresas y como poder adquisitivo para los trabajadores de las entidades.

En cuanto al salario real medido como costo laboral, el deterioro para el total de las empresas públicas de la SIGEP fue de -20,7\% entre 1974 y 1983. Esto contrasta con el ritmo ascendente del salario real durante los años previos, que tuvo exactamente la misma variación porcentual, pero con signo positivo de 20,7\% entre 1966 y 1973 . La caída fue generalizada, no hubo un solo caso que no haya manifestado una variación negativa entre 1974 y 1983, en un claro cambio de tendencia con respecto a la industrialización sustitutiva, ya que entre 1966 y 1973 todas las firmas tuvieron saldos positivos (Gráfico 4). Las empresas que más deterioro en el salario real manifestaron fueron las pertenecientes al subsector eléctrico: en primer lugar, AyEE con una caída de $-38,1 \%$ entre puntas y luego SEGBA con una caída de $-37,0 \%$. Muy cerca de estos niveles se encuentran los casos de OSN, con un deterioro de $-33,9 \%$ como saldo del PRN. Luego, se suman los casos de AA con caída de $-26 \%$, GE con caída de -24,6\%, ENCOTEL con -20,2\%, FA con -19,9\% e YPF con caída de -16,4\%. Las empresas con menor caída en las remuneraciones, entendidas como costo laboral, fueron ENTEL, con un deterioro de $-7,2 \%$ e YCF con caída de -0,4\%. También en el análisis por empresa el

\footnotetext{
${ }^{24}$ Para calcular el salario medio real bruto de las empresas públicas y el agregado de la SIGEP, se tomó el total de las remuneraciones en millones de pesos de 1960 y se lo dividió por la cantidad de agentes en cada caso. Para deflactar, tanto el Índice de Precios Mayoristas No Agropecuarios como el Índice de Precios al Consumidor se obtuvieron de la Revista Coyuntura y Desarrollo de la Fundación de Investigaciones para el Desarrollo (FIDE), específicamente el anexo estadístico XVII de abril 1984.
} 
contraste con el final de la ISI es importante, ya que todos los casos habían tenido variación positiva entre 1965 y 1973. Los casos de mayor contraste entre un modelo de acumulación y el otro son los de SEGBA y AA, que pasaron de tener remuneraciones muy positivas como saldo de la ISI a estar entre las empresas que más perdieron hacia el final del PRN (Gráfico 4).

\section{Gráfico 4 - Evolución del salario real bruto medio de las empresas públicas. Variación porcentual 1966-1973 (ISI) y 1974-1983 (PRN)}

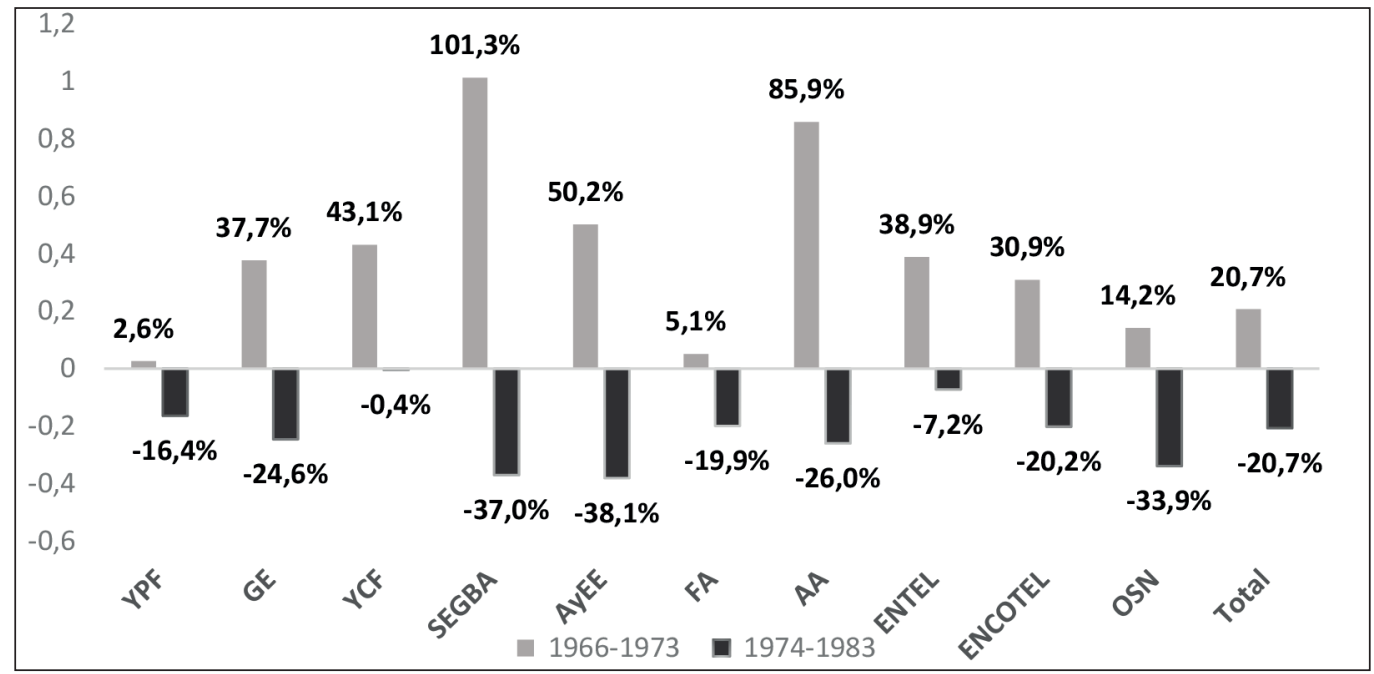

Fuente: elaboración propia en base a datos de la SIGEP (1984, p. 16-19).

Cuando se analiza la evolución del salario real bruto medio en las empresas públicas deflactado por el IPC, se constata que las pérdidas reales fueron más moderadas, de $-5,8 \%$ entre 1974 y 1983 para el total de la SIGEP. Esto se debe, en gran medida, a una variación distinta en los precios que componen la canasta de un índice y otro. La canasta con la que se calcula el IPMNA tiene mayor presencia de bienes que la del IPC, por lo tanto, se ve más afectado por los sucesivos incrementos en el tipo de cambio, mediante el pass through. La canasta que compone el IPC tiene, como contracara, mayor presencia de servicios en su composición, razón por la que se vio más afectada por la política de precios y tarifas rezagadas en los servicios públicos. Una interpretación alternativa por la que el costo laboral haya caído más que el poder adquisitivo de los trabajadores puede ser la reducción de las contribuciones patronales, a partir de la reforma previsional puesta en macha por parte de la gestión de Martínez de Hoz. Como es predecible, en el análisis por empresa también se constata esta mengua en la caída del salario real cuando se deflacta por el salario real (Tabla 7). 
Tabla 7 - Evolución del salario real bruto medio de las empresas públicas, 1974-1983 (en pesos argentinos, índice base $1974=100$ y porcentajes) ${ }^{\star}$

\begin{tabular}{c|r|c|c|c|c|c}
\hline Años & \multicolumn{7}{|c}{ Total empresas públicas SIGEP } \\
\hline 1974 & Pesos ley 18188 & Deflactor & $\begin{array}{c}\text { Cantidad } \\
\text { de agentes }\end{array}$ & $\begin{array}{c}\text { Salario real } \\
\text { bruto medio }\end{array}$ & $\begin{array}{c}\text { Índice base } \\
1974=100\end{array}$ & $\begin{array}{c}\text { Var. } \\
\text { interanual } \\
\%\end{array}$ \\
\hline 1974 & 19.569 .400 .000 & 19.569 .400 .000 & 393.942 & $49.675,840606$ & 100,0 & \\
\hline 1975 & 61.258 .700 .000 & 21.948 .656 .396 & 424.923 & $51.653,255756$ & 104,0 & 4,0 \\
\hline 1976 & 228.332 .800 .000 & 15.334 .640 .698 & 419.371 & $36.565,810937$ & 73,6 & $-29,2$ \\
\hline 1977 & 529.740 .200 .000 & 13.040 .721 .776 & 373.472 & $34.917,535388$ & 70,3 & $-4,5$ \\
\hline 1978 & 1.522 .531 .500 .000 & 13.599 .130 .924 & 344.478 & $39.477,501971$ & 79,5 & 13,1 \\
\hline 1979 & 4.331 .532 .700 .000 & 14.908 .404 .952 & 332.594 & $44.824,635899$ & 90,2 & 13,5 \\
\hline 1980 & 9.162 .370 .000 .000 & 15.707 .575 .230 & 309.554 & $50.742,601389$ & 102,1 & 13,2 \\
\hline 1981 & 15.896 .021 .000 .000 & 13.327 .448 .505 & 296.623 & $44.930,597103$ & 90,4 & $-11,5$ \\
\hline 1982 & 32.420 .370 .000 .000 & 10.265 .896 .997 & 288.828 & $35.543,288729$ & 71,6 & $-20,9$ \\
\hline 1983 & 197.420 .000 .000 .000 & 14.085 .555 .157 & 301.043 & $46.789,180140$ & 94,2 & 31,6 \\
\hline $\mathbf{1 9 8 3 / 1 9 7 3}$ & & & & & & $\mathbf{- 5 , 8}$ \\
\hline
\end{tabular}

* Deflactado en base al Índice de Precios al Consumidor base $1974=100$

Fuente: elaboración propia en base a SIGEP (1984, p. 16-19); FIDE (1984, p. 5).

\section{Productividad y distribución regresiva del ingreso}

Entre 1974 y 1983 la productividad laboral ${ }^{25}$ en las empresas públicas se incrementó a una tasa de variación anual acumulativa de 4,9\% para el total de la SIGEP. Esta variación es superior a la acaecida en los años previos, para los cuáles se tienen datos comparables, ya que entre 1970 y 1973 la tasa de variación anual acumulativa fue de $3,2 \%{ }^{26}$. Esa relación de mayor dinamismo en la productividad laboral durante la dictadura con respecto a los cuatro años previos se mantiene, además, en la mayor parte de las empresas bajo análisis, con excepción de GE, AA y ENCOTEL. La primera, con crecimiento del producto por ocupado entre 1974-1983 (3,8\%) aunque con menor dinamismo que entre 1970 y 1973; AA siguió la misma dinámica que

\footnotetext{
${ }^{25}$ El cálculo de productividad laboral se efectuó en base al producto en millones de pesos de 1970, divido por la cantidad de agentes.

${ }^{26}$ Los datos de producto bruto interno de las empresas públicas que comprenden la totalidad del período bajo análisis (1974-1983) están expresados en millones de pesos de 1970, a diferencia de otros indicadores que están expresados en millones de pesos de 1960, permitiendo una comparación hacia atrás más extensa.
} 
GE, aunque con una disminución más importante entre períodos, probablemente porque AA fue la única empresa cuya dotación de trabajadores no se redujo durante el PRN y, por último, ENCOTEL que fue la única con productividad laboral negativa entre 1974-1983. En el resto de los casos la productividad laboral de la dictadura superó los años previos considerando, además, que muchas empresas tuvieron productividad laboral negativa entre 1970 y 1973 (YPF, YCF, FA). La empresa que más incremento tuvo fue AyEE, con una suba de 11,3\% entre puntas y el resto de los casos rondó en crecimientos entre el 3\% y el 6\%. En suma, el incremento del producto por ocupado fue muy significativo en las empresas públicas entre 1974-1983 (Tabla 8).

Pero más allá de la dimensión cuantitativa, lo más destacable en cuanto al incremento de la productividad laboral en las empresas públicas se desprende de su relación con la dinámica del empleo. Mientras que los años previos al golpe militar el incremento (más moderado) en la productividad fue acompañado de un crecimiento en la producción y en el empleo en simultáneo; entre 1974 y 1983 se constata un incremento en el volumen físico de la producción, junto con una significativa contracción en la dotación de trabajadores del conjunto de las entidades. De manera análoga a lo que señalan Azpiazu et al., (1986) para la industria manufacturera, durante la ISI el incremento de la productividad conllevó un aumento de la capacidad productiva del trabajo en las empresas públicas, ya que no hubo reducción en sus planteles. Por el contrario, luego del golpe militar del 76, el incremento en la productividad laboral estuvo vinculado a un proceso ininterrumpido de expulsión de mano de obra. El caso de AyEE es paradigmático ya que fue, al mismo tiempo, la empresa que más incrementó su producto por ocupado y la que más redujo la dotación de personal. Este fenómeno indica que, más allá del mayor volumen de producción, los trabajadores se vieron sometidos a una mayor intensidad en el uso de su fuerza de trabajo, en base a diversos mecanismos "disciplinadores" tales como la extensión de la jornada de laboral, cercenamiento de las conquistas laborales, entre otros. En Iramain y Ascencio, (2020) se analizan algunos indicadores que dan cuenta de dicho "disciplinamiento" hacia los trabajadores de la SIGEP entre 1976 y 1983, en base a la drástica reducción de los conflictos gremiales durante la etapa más alta de la represión (entre 1976 y 1981) y también la reducción abrupta de la tasa de ausentismo y accidentes laborales. 
Tabla 8 - Evolución de la productividad laboral (producto por ocupado) de las empresas públicas, $\star 1970-1983$. Variación interanual 1974-1983. Tasa de variación anual acumulativa 1970-1973 (ISI) y 1974-1983 (PRN)

\begin{tabular}{|c|c|c|c|c|c|c|c|c|c|c|c|c|c|c|c|c|c|c|c|c|c|c|}
\hline \multirow[t]{2}{*}{ 离 } & \multicolumn{2}{|c|}{$\overbrace{\lambda}^{L}$} & \multicolumn{2}{|c|}{ 닌 } & \multicolumn{2}{|c|}{ 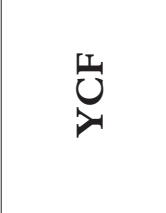 } & \multicolumn{2}{|c|}{$\underset{\substack{n \\
0}}{*}$} & \multicolumn{2}{|c|}{ 峌 } & \multicolumn{2}{|c|}{$\mathbb{I}$} & \multicolumn{2}{|c|}{ 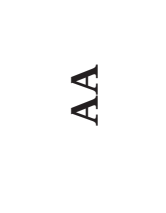 } & \multicolumn{2}{|c|}{$\begin{array}{l}\text { 空 } \\
\text { 至 } \\
\text { 至 }\end{array}$} & \multicolumn{2}{|c|}{ 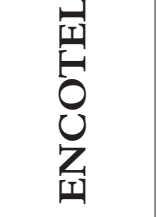 } & \multicolumn{2}{|c|}{\begin{tabular}{l}
$*$ \\
\multirow{*}{*}{} \\
$Z$ \\
0 \\
0
\end{tabular}} & \multicolumn{2}{|c|}{ 룽 } \\
\hline & $\begin{array}{l}\overrightarrow{0} \\
0 \\
0\end{array}$ & مْ & 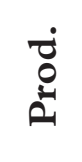 & مُ & $\begin{array}{l}\overrightarrow{0} \\
0 \\
0 \\
0\end{array}$ & & $\begin{array}{l}\overrightarrow{0} \\
0 \\
0 \\
0\end{array}$ & مْ & $\begin{array}{l}\overrightarrow{0} \\
0 \\
0\end{array}$ & 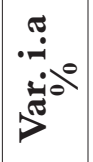 & $\begin{array}{l}\overrightarrow{0} \\
0 \\
0 \\
0\end{array}$ & 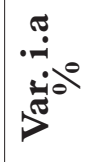 & Dं & مْ & $\begin{array}{l}\overrightarrow{0} \\
0 \\
0 \\
0\end{array}$ & 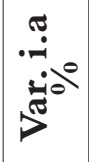 & $\begin{array}{l}\overrightarrow{0} \\
\stackrel{0}{0} \\
0\end{array}$ & & $\begin{array}{l}\dot{0} \\
\dot{0} \\
\dot{0}\end{array}$ & : & i & 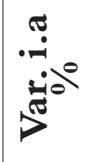 \\
\hline 1970 & 53,4 & & 40,6 & & 12,7 & & 22,5 & & 21,8 & & 6,7 & & 23,4 & & 14,1 & & 6,3 & & 7,3 & & 14,8 & \\
\hline 1971 & 55,6 & 4,1 & 43,9 & 8,2 & 12,0 & $-5,3$ & 25,3 & 12,4 & 23,1 & 6,2 & 6,5 & $-2,5$ & 26,4 & 13,1 & 14,0 & $-0,6$ & 6,4 & 2,3 & 7,5 & 2,2 & 15,6 & 5,3 \\
\hline 1972 & 54,7 & $-1,6$ & 45,0 & 2,5 & 13,2 & 9,2 & 26,4 & 4,1 & 22,8 & $-1,2$ & 6,5 & $-0,2$ & 29,9 & 13,0 & 14,4 & 2,2 & 6,4 & 0,3 & 7,9 & 5,5 & 16,1 & 3,2 \\
\hline 1973 & 51,0 & $-6,9$ & 48,4 & 7,4 & 8,1 & $-38,5$ & 26,4 & 0,1 & 23,0 & 0,6 & 6,6 & 2,1 & 31,7 & 6,0 & 14,3 & $-0,3$ & 7,0 & 7,9 & 7,7 & $-2,7$ & 16,2 & 1,0 \\
\hline 1974 & 46,4 & $-9,0$ & 46,8 & $-3,1$ & 7,1 & $-11,9$ & 22,0 & $-16,8$ & 22,6 & $-1,7$ & 6,8 & 2,4 & 37,7 & 18,8 & 15,7 & 9,6 & 7,0 & 0,6 & 6,7 & $-12,6$ & 16,1 & $-0,9$ \\
\hline 1975 & 37,9 & $-18,3$ & 44,9 & $-4,2$ & 6,8 & $-5,1$ & 21,2 & $-3,3$ & 18,2 & $-19,4$ & 6,1 & $-9,8$ & 37,0 & $-1,7$ & 14,8 & $-5,9$ & 5,0 & $-27,9$ & 7,1 & 6,2 & 14,5 & $-9,9$ \\
\hline 1976 & 39,8 & 5,0 & 49,9 & 11,3 & 7,7 & 13,9 & 22,1 & 4,1 & 19,5 & 7,1 & 6,1 & $-0,9$ & 34,7 & $-6,2$ & 15,0 & 2,0 & 4,6 & $-8,1$ & 7,2 & 0,0 & 14,7 & 1,4 \\
\hline 1977 & 47,9 & 20,6 & 50,7 & 1,6 & 6,6 & $-13,9$ & 28,1 & 27,3 & 23,8 & 22,4 & 6,8 & 12,1 & 42,6 & 22,7 & 16,2 & 7,9 & 5,2 & 11,7 & 7,9 & 11,1 & 17,4 & 18,3 \\
\hline 1978 & 58,0 & 20,9 & 52,0 & 2,5 & 7,2 & 8,7 & 32,5 & 15,6 & 26,5 & 11,2 & 7,3 & 6,7 & 45,4 & 6,7 & 17,6 & 8,7 & 4,6 & $-11,1$ & 8,3 & 4,5 & 19,5 & 12,0 \\
\hline 1979 & 64,3 & 10,9 & 53,5 & 2,9 & 12,4 & 71,5 & 39,4 & 21,3 & 34,0 & 28,1 & 7,9 & 8,8 & 52,4 & 15,3 & 19,1 & 8,1 & 4,9 & 6,3 & 8,7 & 5,2 & 22,4 & 15,0 \\
\hline 1980 & 70,5 & 9,6 & 56,9 & 6,3 & 6,9 & $-44,0$ & 38,2 & $-3,2$ & 36,0 & 6,0 & 8,3 & 4,6 & 58,7 & 12,1 & 20,5 & 7,7 & 5,6 & 13,8 & 8,1 & $-7,0$ & 24,5 & 9,5 \\
\hline 1981 & 73,8 & 4,8 & 58,0 & 1,9 & 9,0 & 30,1 & 40,3 & 5,7 & 49,8 & 38,3 & 7,4 & $-10,6$ & 52,0 & $-11,4$ & 20,8 & 1,3 & 5,4 & $-2,8$ & 10,5 & 29,3 & 24,7 & 0,6 \\
\hline 1982 & 74,1 & 0,4 & 61,3 & 5,7 & 10,5 & 16,8 & 37,2 & $-7,8$ & 55,2 & 10,7 & 8,1 & 9,8 & 45,1 & $-13,4$ & 22,9 & 10,0 & 5,4 & $-0,9$ & 11,5 & 9,2 & 25,0 & 1,3 \\
\hline 1983 & 70,7 & $-4,6$ & 65,4 & 6,7 & 9,2 & $-13,1$ & 36,5 & $-1,8$ & 59,3 & 7,6 & 9,1 & 11,2 & 45,6 & 1,2 & 23,3 & 1,6 & 5,1 & $-4,9$ & 11,5 & 0,5 & 24,7 & $-0,9$ \\
\hline $\begin{array}{c}1974- \\
1983\end{array}$ & & 52,4 & & 39,7 & & 28,6 & & 66,4 & & 162,7 & & 33,0 & & 21,1 & & 48,3 & & $-27,0$ & & 71,4 & & 53,7 \\
\hline $\begin{array}{c}\text { TVAA } \\
1970- \\
1973\end{array}$ & & $-1,5$ & & 6,0 & & $-14,0$ & & 5,4 & & 1,8 & & $-0,2$ & & 10,7 & & 0,4 & & 3,5 & & 1,6 & & 3,2 \\
\hline $\begin{array}{c}\text { TVAA } \\
1974- \\
1983\end{array}$ & & 4,8 & & 3,8 & & 2,8 & & 5,8 & & 11,3 & & 3,2 & & 2,1 & & 4,5 & & $-3,4$ & & 6,2 & & 4,9 \\
\hline
\end{tabular}

* La productividad laboral se calculó en base al producto a costo de factores expresado en millones de \$ de 1970 por la cantidad de agentes

Fuente: elaboración propia en base a SIGEP (1984, p. 33). 
Una forma de interpretar este proceso surge del análisis de la relación productividad - salarios. Tal como se observa en el Gráfico 5, a partir de 1976 la productividad estuvo siempre por encima de las remuneraciones, lo que condujo a un aumento muy destacado del superávit bruto de explotación ${ }^{27}$, que puede observarse en la distancia entre el incremento de la productividad y la caída en los salarios reales.

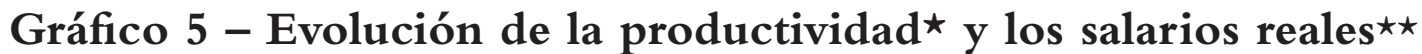 en las empresas públicas, 1974-1983. Índice base $1974=100$}

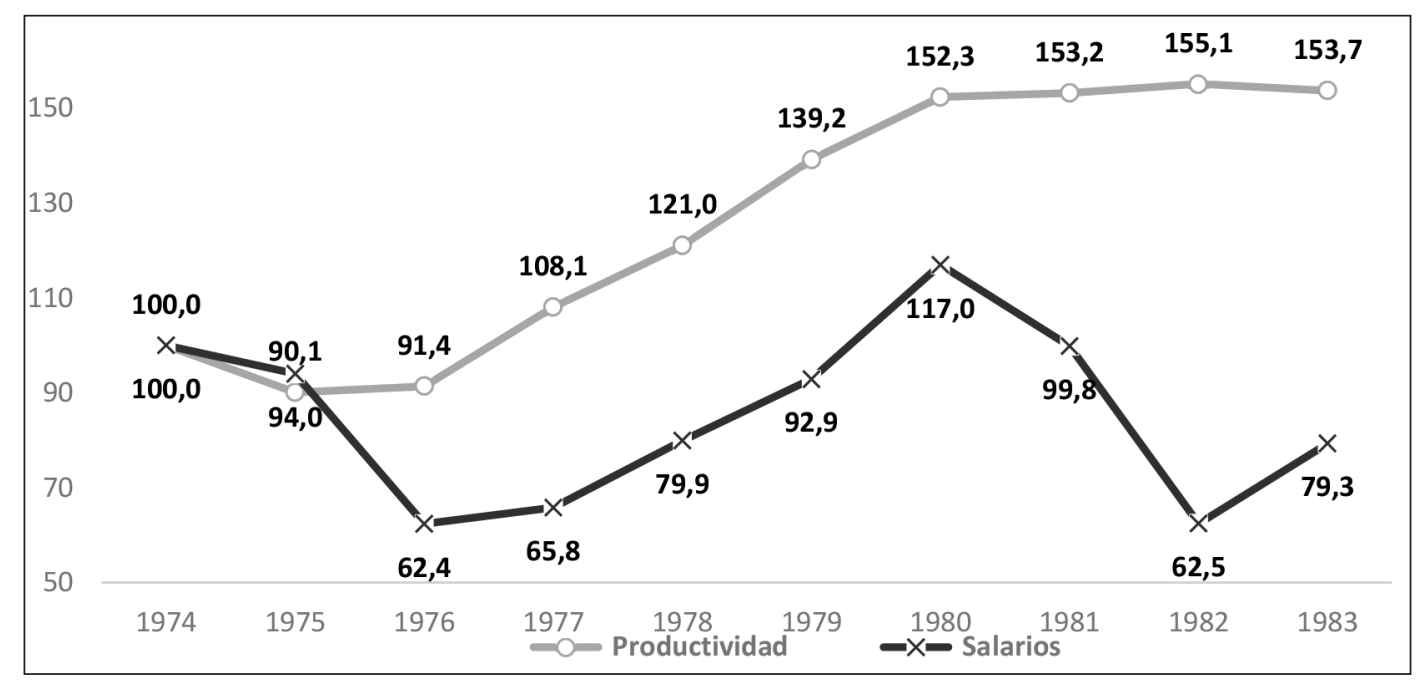

$\star$ En base al producto (en millones de pesos de 1970) por ocupado (cantidad de agentes).

$\star \star$ Deflactado por el IPMNA.

Fuente: elaboración propia en base a $\operatorname{SIGEP}(1984$, p. 15 y 19).

Esta relación constituye un indicador proxy de la intensificación de la explotación de la fuerza de trabajo y del concomitante aumento de los excedentes a disposición de las firmas estatales. En efecto, el desacople entre el incremento en la productividad y la política de "racionalización" y deterioro del salario real introdujo una dinámica regresiva en la distribución del ingreso al interior de las firmas, dado que el aumento significativo del excedente no fue apropiado por los trabajadores. No obstante, eso no indica que los excedentes fueran efectivamente apropiados por las empresas públicas, sino que en muchos casos fueron transferidos vía precios y tarifas rezagadas hacia los consumidores y/o usuarios privados de los servicios públicos, probablemente compuestos por grandes firmas privadas industriales y comerciales (Azpiazu, Basualdo y Khavisse, 1986; Castellani e Iramain, 2018).

\footnotetext{
${ }^{27}$ El término es empleado por Boneo, (1980) para el análisis de la relación valor agregado-remuneraciones de los trabajadores en las empresas públicas.
} 


\section{Reflexiones finales}

En lo relativo a las capacidades técnico-operativas, el producto bruto interno de las firmas creció entre 1974 y 1983 motorizado por un incremento del volumen físico, aunque con un ritmo de crecimiento menor comparado a los últimos años de la ISI. Al mismo tiempo, los precios y las tarifas de las firmas tuvieron una dinámica decreciente que posibilitó la transferencia de ingresos hacia los usuarios de los servicios provistos por las empresas públicas. Una vía sugerente para futuras indagaciones consiste en la delimitación y caracterización de los actores beneficiarios de este tipo de transferencias. Ahora bien, el principal rasgo del período fue el cambio cualitativo que se produjo en relación producción-empleo. Durante la industrialización sustitutiva, el nivel de actividad de las empresas públicas creció junto con el empleo y los salarios, es decir, que se incrementó la capacidad productiva del empleo. A partir de 1976, la dotación de trabajadores y el nivel de los salarios se deterioraron incrementando del superávit bruto de explotación. Esto constituye, según el marco teórico empleado, un indicador del retroceso en las capacidades examinadas en este artículo. La dinámica regresiva en materia laboral durante la última dictadura fue un rasgo generalizado, en particular en el sector público, donde se produjeron despidos constantes en base al concepto de "prescindibilidad" de los empleados públicos. Ahora bien, el proceso de "racionalización" de los planteles laborales en la SIGEP fue aún más intenso que en el sector público nacional, con una caída del -23,6\%, lo que implicó la expulsión de 92.899 de trabajadores entre 1974 y 1983. Por otra parte, la reducción del personal ocupado no se dio con igual intensidad en todos los niveles de calificación, sino que tuvo mayor preeminencia en el personal obrero, técnico y especializado, en base al propósito explícito y contradictorio de la propia sindicatura de "jerarquización" de los puestos de trabajo y retención del personal más calificado. Todo lo anterior condujo a un aumento de la productividad laboral muy significativo, basado en la mayor explotación de la fuerza de trabajo.

\section{Referencias}

ARCEO, N.; MONSALVO, A.-P.; SCHORR, M.; WAINER, A. Empleo y salarios en la Argentina: una visión de largo plazo. Buenos Aires: Capital Intelectual, 2008. 
ARONSKIND, R. ¿Más cerca o más lejos del desarrollo? Transformaciones económicas en los '90. Buenos Aires: Libros del Rojas, 2001.

ARONSKIND, R. Controversias y debates en el pensamiento económico argentino. Universidad Nacional de General Sarmiento, 2008.

AZPIAZU, D.; BASUALDO, E.; KHAVISSE, M. El nuevo poder económico e la Argentina de los años 80. Buenos Aires: Siglo XXI, 1986.

AZPIAZU,D.; SCHORR, M. Hecho en Argentina. Industria y Economía, 19761983. Buenos Aires: Siglo XXI, 2010.

BASUALDO, E. Acerca de la naturaleza de la deuda externa y la definición de una estrategia política. Buenos Aires: Universidad Nacional de Quilmes/FLACSO, Página/12, 2000.

BASUALDO, E. Estudios de historia económica argentina: desde mediados de siglo XX a la actualidad. Buenos Aires: Siglo XXI, 2010.

BASUALDO, E. El legado dictatorial. El nuevo patrón de acumulación de capital, la desindustrialización y el ocaso de los trabajadores. In:VERBITSKY, H.; BOHOSLAVSKY,J. P. (Org.). Cuentas pendientes: los cómplices económicos de la dictadura. Buenos Aires: Siglo XXI, p. 81-99, 2013.

BELINI, C.; ROUGIER, M. El Estado empresario en la industria argentina: conformación y crisis. Buenos Aires: Matantial, 2008.

BONEO, H. Regímenes políticos y empresas públicas: algunas cuestiones vinculadas al ámbito y dimensión del sector productivo estatal. Estudios CEDES, v. 3. n. 7, p. 5-35, 1980.

CANELO, P. El proceso en su laberinto: la interna militar deVidela a Bignone. Buenos Aires: Prometeo, 2008.

CANITROT, A. La disciplina como objetivo de la política económica: un ensayo sobre el programa económico del gobierno argentino desde 1976. Desarrollo Económico, v. 19, n. 76, p. 453-175, 1980. 
CASTELLANI, A. Estado, empresas y empresarios. La relación entre la intervención económica estatal, difusión de ámbitos privilegiados de acumulación y desempeño de las grandes firmas privadas. Argentina, 1966-1989. Tesis de Doctorado en Ciencias Sociales. Universidad de Buenos Aires, 2006.

CASTELLANI, A. Gestión económica liberal-corporativa y transformaciones en el interior de los grandes agentes económicos de la Argentina durante la última dictadura militar. In: PUCCIARELLI, A. (Org.). Empresarios, tecnócratas y militares: la trama corporativa de la última dictadura. Buenos Aires: Siglo XXI, p. 173-218, 2004.

CASTELLANI,A.; IRAMAIN, L. El deterioro del Estado-empresario: transformaciones estructurales y desempeño de las empresas públicas argentinas durante la última dictadura (1976-1983). América Latina en la Historia Económica, v. 25, n. 2, p. 239-271, 2018.

FERRERES, O. Dos siglos de economía argentina 1810-2010. Buenos Aires: Fundación del Norte y el Sur, 2010.

FUNDACIÓN DE INVESTIGACIONES PARA EL DESARROLLO (FIDE). Revista Coyuntura y desarrollo, Anexo Estadístico XVII. Buenos Aires: Fundación de Investigaciones para el Desarrollo. 1984.

GAS DEL ESTADO. Boletín Estadístico Anual 1983.1984.

HEREDIA, M. El Proceso como bisagra: emergencia y consolidación del liberalismo tecnocrático: FIEL, FM y CEMA. In: PUCCIARELLI,A. (Org.). Empresarios, tecnócratas y militares: la trama corporativa de la última dictadura. Buenos Aires: Siglo XXI, p. 313-382, 2004.

IRAMAIN, L. Política económica en la dictadura: la orientación y calidad de la intervención económica del Estado en el sector vial. La actuación de la Dirección Nacional deVialidad (DNV) (Argentina, 1976-1981). Buenos Aires: Documentos de investigación social, 2014.

IRAMAIN, L. Privatización periférica, descentralización y regionalización: el desempeño de ENTEL en la gestión liberal-corporativa de Martínez de 
Hoz (1976-1981). Ciclos en la historia, la economía y la sociedad, v. 24, n. 45, p. 21-36, 2015.

IRAMAIN, L.; ASCENCIO, D. La relación capital-trabajo en el Estado empresario: un análisis de los indicadores laborales en las empresas públicas. In: ZORZOLI, L.; MASSANO, J. P. Clase obrera y dictadura militar en Argentina (1986-1983): nuevos estudios sobre conflictividad y cambios estructurales. Buenos Aires: A Contracorriente, p. 366-398, 2021.

ODISIO, J. Empresas del Estado y petroquímica en México y Argentina durante la industrialización por sustitución de importaciones. Signos históricos, v. 17, p. 35-45, 2018.

PUCCIARELLI, A. La patria contratista: el nuevo discurso liberal de la dictadura militar encubre una vieja práctica corporativa. In: PUCCIARELLI, A. (Org.). Empresarios, tecnócratas y militares: la trama corporativa de la última dictadura. Buenos Aires: Siglo XXI, p. 99-172, 2004.

RECALDE, H. Supresión de los derechos de los trabajadores.VERBITSKY, Horacio; Bohoslavsky, J. P. (Org.). Cuentas pendientes: los cómplices económicos de la dictadura, Buenos Aires: Siglo XXI, p. 255-272, 2013.

REGALSKY,A.; ROUGIER, M. Los derroteros del Estado empresario en Argentina. Buenos Aires: EDUNTREF, 2015.

REVISTA Prensa Económica. CDI-MECON.

ROBERTINI, C. El disciplinamiento de la clase trabajadora durante la última dictadura militar argentina. Iberoamérica Social: revista-red de estudios sociales, v. 1, 10-24, 2016.

ROUGIER, M. Empresarios de uniforme. La conformación de un complejo militar - industrial en la Argentina. In: GUAJARDO SOTO, G.;LABRADOR, A. La empresa pública en México y América Latina: entre el mercado y el Estado. Ciudad de México: Universidad Nacional Autónoma de México, p.327-343, 2015.

ROUGIER, M.; ODISIO, J. El “canto del cisne” de la industrialización en 
Argentina. Desempeño y alternativas en la etapa final de la ISI. Revista Estudios Sociales, p. 51-67, 2019.

SCHORR, M. Industria y Nación. Poder económico, neoliberalismo y alternativas de reindustrialización en la Argentina Contemporánea. Buenos Aires: Edhasa, 2004.

SCHORR, M. La desindustrialización como eje del proyecto refundacional de la economía y la sociedad argentina (1976-1983). América Latina en la Historia Económica, v. 19, p. 31-56, 2012.

SCHVARZER, J. Empresas públicas y desarrollo industrial en Argentina. Economía de América Latina, v. 3, p. 45-68, 1979.

SCHVARZER, J. Expansión económica del Estado subsidiario 1976-1981. Buenos Aires: Centro de Investigaciones Sociales sobre el Estado y la Administración, 1981.

SCHVARZER, J. La política económica de Martínez de Hoz. Buenos Aires: Hyspanoamérica, 1986.

SCHVARZER, J. Implantación de un modelo económico: la experiencia argentina entre 1975 y el 2000. Buenos Aires: AZ Editora, 1998.

SIMONASSI, S. “A trabajar y muzzarella”. Prácticas y políticas de disciplinamiento laboral en la industria metalúrgica de Rosario, 1974-1983. Historia regional, v. 3, n. 25, p. 57-82, 2007.

SINDICATURA GENERAL DE EMPRESAS PÚBLICAS (SIGEP). Boletín Nacional, n. 20 - Anuario 1981. Reproducido en Secretaría de Comercio, Dirección Nacional de Investigaciones Sectoriales. Buenos Aires: SIGEP. Junio de1982

SINDICATURA GENERAL DE EMPRESAS PÚBLICAS (SIGEP). Divulgación, n. 12. Buenos Aires: SIGEP. Noviembre de 1985.

SINDICATURA GENERAL DE EMPRESAS PÚBLICAS (SIGEP). Divulgación, n. 6. Buenos Aires: SIGEP. Noviembre de 1983. 
SINDICATURA GENERAL DE EMPRESAS PÚBLICAS (SIGEP). PBI de Empresas Públicas Argentinas. En valores constantes 1950-1981. Serie de Estudios Técnicos. Buenos Aires: SIGEP. Mayo de 1983.

SINDICATURA GENERAL DE EMPRESAS PÚBLICAS (SIGEP). Evolución de las principales relaciones económicas, de producción, ocupación y precios de las empresas públicas, 1965-1987. Serie de Estudios Técnicos, n. 45. Buenos Aires: SIGEP. Julio de 1988.

SINDICATURA GENERAL DE EMPRESAS PÚBLICAS (SIGEP). Nivel de actividad. Notas sobre la metodología. Aspectos conceptuales y cuantitativos. Buenos Aires: CTP; SIGEP. Diciembre de 1980.

SINDICATURA GENERAL DE EMPRESAS PÚBLICAS (SIGEP). Síntesis estadística anual, año 1983. Buenos Aires: SIGEP. 1984.

YACIMIENTOS PETROLÍFEROS FISCALES (YPF). Anuarios Estadísticos de 1978, 1982, 1983, 1982. CDI-MECON. 